\title{
El concepto de educación: \\ La confluencia de criterios de definición, orientación formativa temporal y actividad común como núcleo de contenido de su significado The concept of education: The confluence of criteria of definition, temporal formative orientation and common activity as a nucleus of content of its meaning
}

José Manuel TOURIÑÁN LÓPEZ ${ }^{1}$

Catedrático de Teoría de la Educación

Universidad de Santiago de Compostela

Premio Internacional Educa-Redipe 2019 (Trayectoria profesional).

1 José Manuel Touriñán López

Nació en 1951. Maestro de Enseñanza Primaria (1969). Licenciado (1974) y Doctor (1978) en Pedagogía con premio extraordinario en ambos casos. Catedrático de Universidad (1988). Evaluador-auditor de programas universitarios, proyectos de investigación y publicaciones científicas en organismos oficiales y revistas profesionales. Autor de más de 250 estudios (en forma de artículos de revistas de investigación y capítulos de libros especializados), 40 libros escritos como autor único y 10 más en coautoría. Ha recibido premios autonómicos, nacionales e internacionales. Su trayectoria profesional ha sido biografiada en repertorios europeos y americanos. Es coordinador de la red RIPEME (Red internacional de pedagogía mesoaxiológica), integrada en la Red iberoamericana de pedagogía (Redipe), y del grupo de investigación Tercera Generación (TeXe), de la Universidad de Santiago de Compostela en la que imparte docencia de Teoría de la Educación, Política de la Educación y Función Pedagógica. Sus líneas de investigación sobre desarrollo de sistemas educativos, intervención pedagógica y función pedagógica convergen actualmente en la línea Pedagogía mesoaxiológica y construcción de ámbitos de educación: valoración del contenido de las áreas de experiencia cultural como educación y fundamentación del conocimiento necesario para la construcción de ámbitos de educación, de manera que se integren en el diseño educativo valores comunes de educación y valores educativos específicos de cada área cultural (Proyecto PIIR 004 Educere Area. Educar con las áreas culturales), disponible en la dirección http:/l dondestalaeducacion.com/files/5615/6485/0752/Proy Educere_Area-Lin Invest_PMyCAE.pdf

Por Resolución de 18 de mayo de 2019, se le ha otorgado el Premio Educa-Redipe 2019 (Trayectoria profesional). Webs Particulares: http://dondestalaeducacion.com/https://www.youtube.com/channel/UCzbNAzwFApNMViix5 HDzOw Researcher ID: http://www.researcherid.com/rid/L-1032-2014Orcid: http://orcid.org/0000-0002-7553-4483 


\section{RESUMEN}

El objetivo de este trabajo es fundamentar la necesidad de ir más allá de la definición nominal del concepto de educación y justificar la existencia de rasgos distintivos de la definición real del término 'educación' en el carácter y el sentido inherentes al significado, que deben ser tenidos en cuenta en cada momento y lugar, siempre que realicemos intervención pedagógica.

Se trata de formar criterio sobre el significado de 'educación' y la importancia de la Pedagogía en la construcción de ámbitos de educación. EI conocimiento de la educación hace posible la construcción de ámbitos de educación con las áreas culturales, transformando la información en conocimiento y el conocimiento en educación. Y esto exige ejercer la función pedagógica con competencia, estableciendo una relación educativa en la que la actividad común es la herramienta de trabajo.

\section{PALABRAS CLAVE}

Pedagogía como disciplina; Concepto de educación; Complejidad de educación; Orientación formativa temporal; Función pedagógica; Relación educativa; Principio de actividad.

\section{CONCEPT OF EDUCATION: CONFLUENCE OF DEFINITION CRITERIA, TEMPORARY FORMATIVE ORIENTATION AND COMMON ACTIVITY AS CORE CONTENT OF ITS MEANING}

\section{ABSTRACT}

In this work, the purpose is to establish the need to go beyond the nominal definition of the concept of education and justify the existence of distinctive traits of the real definition of the term 'education' in character and sense inherent in its meaning, which must be taken into account at all times and places, whenever we carry out pedagogical intervention.
It is about forming criteria on meaning of 'education' and importance of Pedagogy in the construction of education fields. Knowledge of education makes it possible to build fields of education over cultural areas, transforming information into knowledge and knowledge into education. And this requires executing pedagogical function with competence, establishing an educational relationship in which common activity is the working tool.

\section{KEY WORDS}

Pedagogy as a discipline; Concept of Education; Complexity of Education; Temporary Formative Orientation; Pedagogical Function; Educational Relationship; Activity Principle.

\section{INTRODUCCIÓN ${ }^{2}$}

Es una observación común que el verdadero conocimiento de las cosas sólo se alcanza con la experiencia de su frecuente trato, porque este nos permite hacernos una idea de ellas y alcanzar su significado o comprensión, por medio de una personal asimilación. Esto, que en general acontece en todo orden de asuntos, vale, de una manera especial, para la esfera de los conocimientos. De ahí que la comprensión del significado de un término sea más un resultado tardío y reflexivo, que una labor enteramente apriorística sin experiencia previa. Yo escribo este trabajo desde esa convicción.

En general, toda definición puede verificarse de una doble manera: como definición nominal

\footnotetext{
$2 \quad$ El fundamento general de este contenido puede verse en: J. M. Touriñán (2015), Pedagogía mesoaxiológica y concepto de educación. Santiago de Compostela: Andavira, 2aedición de 2016; J. M. Touriñán, (2017a), Mentalidad pedagógica y diseño educativo. De la pedagogía general a las pedagogías aplicadas en la función de educar. Santiago de Compostela: Andavira; J. M. Touriñán (2020a), Pedagogía, competencia técnica y transferencia de conocimiento. La perspectiva mesoaxiológica. Santiago de Compostela: Andavira; J. M. Touriñán, (2021). Pedagogía de las artes. La perspectiva mesoaxiológica. Santiago de Compostela: Andavira. Hay una versión no literal en inglés del contenido de este artículo en publicada en 2021 en RBR 10(1), 28-77.
} 
o como definición real, según se centre, respectivamente, en la palabra o nombre con que designamos a una cosa, o en los rasgos y caracteres peculiares de la cosa nombrada. La definición nominal ofrece, pues, la significación de una palabra; la definición real es expresiva de los caracteres distintivos y singulares de la cosa que se pretende definir.

Es normal, antes de elucidar los rasgos que se identifican en la definición real, considerar la significación de la palabra con la cual la nombramos. El estudio de la palabra se ha especificado en la definición de dos maneras: atendiendo al origen y a su sinonimia. La definición nominal tiene dos modalidades: definición etimológica y definición sinonímica; en el primer caso, el método del que nos valemos para manifestar la significación de un término es el recurso a su origen; en el segundo caso, llegamos al significado buscando su aclaración por medio de otras voces más conocidas y de pareja significación.

El objetivo de este trabajo es fundamentar la necesidad de ir más allá de la definición nominal del concepto de educación y justificar la existencia de rasgos distintivos de la definición real del término 'educación' en el carácter y el sentido inherentes al significado, que deben ser tenidos en cuenta en cada momento y lugar, siempre que realicemos intervención pedagógica. El desarrollo del trabajo se resume en las siguientes tesis:

- $\quad$ La definición nominal es necesaria, pero no es suficiente

- La definición real exige atender a rasgos de carácter y sentido vinculados al objeto 'educación' y al acto educativo

- $\quad$ El concepto de educación se integra en la orientación formativa temporal en cada territorio desde la arquitectura curricular
- $\quad$ Conocer, enseñar y educar no significan lo mismo

- La función pedagógica genera intervención desde la actividad común

- La relación educativa permite pasar del conocimiento a la acción realizando la concordancia valores-sentimientos en cada intervención pedagógica.

- $\quad$ Y precisamente por eso, podremos concluir, por una parte, que el concepto de 'educación' es comprensible como confluencia de significado y orientación formativa temporal en cada intervención, contando con la actividad común interna y externa y, por otra parte, que podemos formar criterio sobre el significado de 'educación' y la importancia de la Pedagogía en la construcción de ámbitos de educación.

En definitiva, se trata de entender que el conocimiento de la educación hace posible la construcción de ámbitos de educación con las áreas culturales, transformando la información en conocimiento y el conocimiento en educación. Es la perspectiva mesoaxiológica de la Pedagogía ${ }^{3}$. Y esto exige ejercer la función

$3 \quad$ La Pedagogía, como disciplina con autonomía funcional, es conocimiento de la educación que valora como educativo cada medio que utiliza: es la perspectiva mesoaxiológica de la Pedagogía. La perspectiva mesoaxiológica se resume, conceptualmente hablando, en los siguientes postulados (Touriñán, 2020a, pp. 262-263):

1. Conocer, enseñar y educar tienen distinto significado el conocimiento de áreas culturales no es el conocimiento de la educación. El conocimiento de la educación fundamenta el nexo entre mentalidad pedagógica específica mirada pedagógica especializada y acción educativa concreta controlada y programada para formar la condición humana individual, social, histórica y de especie de cada educando

2. Transformamos información en conocimiento y conocimiento en educación, ajustándonos al significado de educación, utilizando la actividad común del educando sin la cual es imposible educar y buscando la concordancia entre valores y sentimientos en el paso del conocimiento a la acción

3. La función pedagógica es técnica, no política, aunque la educación sea un asunto de interés político; la decisión en Pedagogía, que es conocimiento de la educación, es tecnoaxiológica (decides técnicamente sobre valores) y mesoaxiológica (valoras los medios como educativos)

4. En perspectiva mesoaxiológica, construimos ámbitos de educación hacemos el diseño educativo pertinente y generamos la intervención pedagógica 
pedagógica con competencia, estableciendo una relación educativa en la que la actividad común interna y externa es la herramienta de trabajo.

\section{EL PUNTO DE PARTIDA HACIA LA DEFINICIÓN REAL DE EDUCACIÓN ESTÁ EN EL USO COMÚN DEL TÉRMINO Y EN LAS ACTIVIDADES QUE SE REALIZAN}

Por principio de significado, la definición real nos exige, además de discernir y definir, entender, o sea, nos exige saber en sentido pleno: 1) demostrar la necesidad lógica de unos caracteres o rasgos constitutivos, 2) razonar teórica y prácticamente sobre sus principios y 3) calibrar la impresión de realidad que nos trasmiten. Por consiguiente, tiene sentido afirmar que la indefinición del significado es una fuente constante de mala comprensión $y$ de consideraciones erróneas. Cuando el significado es ambiguo, interpretamos mal a otras personas, a otras cosas y a nosotros mismos: por ambigüedad, distorsionamos y tergiversamos (Dewey, 1998, p. 140).

Desde la perspectiva de la definición nominal y de la finalidad, vinculada a las actividades, 'educar' es, básicamente, adquirir en el proceso de intervención un conjunto de conductas que capacitan al educando para decidir y realizar su proyecto personal de vida y construirse a sí mismo, utilizando la experiencia axiológica para dar respuesta, de acuerdo con la oportunidades, a las exigencias que se plantean en cada situación; se trata de que el educando adquiera conocimientos, actitudes y destrezas-

atendiendo a principios de educación y a principios de intervención que se justifican con el conocimiento de la educación

5. Usamos la actividad común de manera controlada para lograr actividad educada y educar la actividad con mentalidad pedagógica específica y mirada pedagógica especializada desde los elementos estructurales de la intervención, porque sin la actividad común es imposible educar y gracias a ella se hace posible que el educando sea agente actor y cada vez mejor agente autor de su propios proyectos $y$ actos. habilidades-hábitos que lo capacitan, desde cada actividad interna: pensar, sentir afectivamente, querer, elegir-hacer (operar), decidir-actuar (proyectar) y crear (construir simbolizando), y desde cada actividad externa (juego, trabajo, estudio, intervención, indagación-exploración y relación), para elegir, comprometerse, decidir y realizar sus proyectos, dando respuesta de acuerdo con las oportunidades a las exigencias que se plantean en cada situación (Touriñán, 2014a).

Desde la perspectiva de la definición nominal y de la actividad, se afirma que la actividad educativa es "educativa", porque tiene la finalidad de educar y ajusta el significado a los criterios de uso común del término, igual que cualquier otra entidad que se defina nominalmente $y$ sea comprensible. Los criterios de uso común del término y los criterios vinculados a las actividades nos permiten discernir y vincular la definición a la finalidad: el concepto de educación queda demarcado en la misma medida que se cumplan los criterios de uso común del término y se preserve la finalidad de educar. Pero eso es necesario, aunque no es suficiente, si queremos hacer una definición real.

\subsection{El concepto de educación se vincula nominalmente a criterios de uso común del término}

Hoy es frecuente escuchar frases que reflejan los usos más comunes de educación: ¿Se ha pasado de moda la buena educación?; ¿Dónde está el civismo?; ¿Dónde está la cortesía?; ¿Tiene alguna utilidad respetar las normas sociales?; La amabilidad no se premia y no es habitual; ahora, más que nunca, la ignorancia es muy osada y se disculpa, como si fuera ingenuidad; no parece que esté formado; hay que darle un barniz, hay que perfeccionarlo; este chico está malcriado". Todas esas frases inciden en las manifestaciones más tradicionales del uso común de 'educado'. 
Las formas más tradicionales que el uso común hace del significado de educación proceden de nuestra experiencia colectiva histórica y en muy diversos autores y pasajes históricos encontramos argumentaciones que se han transmitido como acervo cultural colectivo y forman parte de la experiencia y de la memoria colectiva que identifica la educación en los siguientes usos comunes: 1) la educación es cortesía, civismo y urbanidad; 2) la educación es crianza material y espiritual; 3) la educación es perfeccionamiento; 4) la educación es formación.

De manera sintética los criterios vinculados al uso del lenguaje común se agrupan en cuatro apartados: Criterios de contenido, forma, uso formativo y equilibrio (Esteve, 2010, pp. 21-28; Peters, 1969 y 1979; Touriñán, 2015; SI(e)TE, 2016):

a) Algo es educación, porque obedece a un criterio axiológico de contenido: no calificamos de educativos a aquellos procesos en los que aprendemos algo que va en contra de los valores, y esto quiere decir que solo calificamos de educativo el aprendizaje de contenidos axiológicamente irreprochables. Defender algo como educativo, implica un juicio de valor sobre el contenido que se utiliza. Si no se logra esto, estamos simplemente en proceso de comunicación, de enseñanza y de aprendizaje.

b) Algo es educación, porque obedece a un criterio ético de forma: no consideramos educativo actuar sobre un educando sin que se respete su libertad o su dignidad como persona. El proceso educativo debe respetar la dignidad y la libertad del educando, porque es también agente de su propio desarrollo. Si no se logra esto, estamos en proceso de instrumentalización.

c) Algo es educación, porque obedece a un criterio de uso formativo: no calificamos de educativos aquellos aprendizajes en los que el educando repite algo que no entiende y que no sabe cómo usar. El proceso educativo debe hacer posible el desarrollo en el educando de algún tipo de esquema conceptual propio sobre lo que se le comunica. Si no se logra esto, no educamos, solo estamos en procesos de información, instrucción, entrenamiento y adiestramiento memorístico.

d) Algo es educación, porque obedece a un criterio de equilibrio en el desarrollo: hablar de educación exige que se consiga una personalidad integrada sin que el desarrollo excesivo o unilateral de una de las áreas de experiencia produzca hombres y mujeres desequilibrados. El proceso educativo reclama siempre resultados equilibrados. Tanto si hablamos de formación general, como de formación especializada, hablamos de formación construida sobre el principio de educación equilibrada. Si no se logra esto, no educamos, estamos en proceso de especialismo.

\subsection{Conocer, enseñar y educar no} significan lo mismo. El conocimiento de la educación determina el concepto de ámbito de educación sobre el conocimiento de áreas culturales

El nivel de las investigaciones pedagógicas actuales permite afirmar que hay razones suficientes para distinguir y no confundir en el lenguaje técnico el conocimiento de la educación y los conocimientos de las áreas culturales.

Es verdad que, desde el punto de vista antropológico, la educación es cultura y, por tanto, tiene sentido afirmar que la función del profesional de la educación es transmitir cultura. Pero, si además afirmamos que los términos educacionales carecen de contenido propio, los conocimientos de las diversas áreas culturales se convierten en el eje de toda actividad pedagógica hasta el extremo de que los mismos profesionales de la educación tendrían que llegar a aceptar, por coherencia, que su formación es simplemente el conocimiento de 
esas áreas culturales y que conocer, enseñar y educar serían la misma cosa. Para mí, por principio de significado, conocer un área cultural no es enseñar, porque el conocimiento puede estar separado de la acción y enseñar no es educar, porque podemos afirmar que hay enseñanzas que no educan, con fundamento en el significado propio de esos términos (Touriñán, 2016 y 2017b; SI(e)TE, 2016).

En relación con las áreas culturales, es verdad que el conocimiento del área cultural es un componente de la acción educativa, pero el conocimiento del área cultural tiene un protagonismo distinto cuando hablamos de "conocer un área cultural", "enseñar un área cultural" y "educar con un área cultural". Esto que decimos, es obvio, si pensamos en un caso concreto, pues no es lo mismo "conocer Historia", que "enseñar Historia" que "educar con la Historia", y así sucesivamente con cada área de experiencia que se constituye en objeto de enseñanza y ámbito de educación.

Desde el punto de vista del conocimiento de la educación, al que enseña se le requiere un determinado nivel de formación relativo al conocimiento del área que será objeto de la enseñanza (área de experiencia y formas de expresión adecuadas al área), pero de ahí no se sigue que enseñar un área sea conocer esa área y que educar sea simplemente enseñar el contenido del área. Es innegable, dado el actual desarrollo del conocimiento de la educación, que todos los profesores no requieren el mismo nivel de pericia en el área cultural de experiencia que enseñan (varía según cuál sea su nivel de ubicación en el sistema educativo), y que todos los profesores no deben tener el mismo conocimiento pedagógico, porque este depende de cuál sea el nivel del sistema educativo en el que se trabaje.

Conocer, en el amplio sentido de rendimiento identificado con las expresiones "sé qué, sé cómo y sé hacer", no se confunde con enseñar.
Aptitudes y competencias para conocer y aptitudes y competencias para enseñar no se subsumen unas en las otras, ni tampoco ambas vacían de significado a la expresión "educar con" un área cultural (Touriñán, 2015, 2019c, 2018 y 2017a). El análisis detenido del contexto pedagógico da pie para sostener que el conocimiento de las áreas culturales no es el conocimiento de la educación y que tiene sentido distinguir conocer, enseñar y educar, porque (Touriñán, 2017a):

a) Si bien es verdad que una buena parte de los objetivos de la educación tiene algo que ver con los contenidos de las áreas culturales en la enseñanza, el ámbito de los objetivos no se agota en los ámbitos de las áreas culturales, ni siquiera en la docencia. La función pedagógica, referida a la docencia, no se agota en saber la información cultural correspondiente a un tema de un área cultural en una clase; antes bien, la función pedagógica se pone de manifiesto cuando se sabe qué tipos de destrezas, hábitos, actitudes, etc., de los diversos dominios que señalan las taxonomías, se están potenciando al trabajar de manera especial en ese tema. La cuestión, en la docencia, no es saber tanto sobre un área como el especialista, sino saber qué objetivos de conocimiento se logran y cómo se logran al enseñar un tema del área y qué destrezas, hábitos, actitudes, conocimientos y competencias estamos desarrollando al enseñar ese tema.

b) La identificación del conocimiento de las áreas culturales con el conocimiento de la educación fomenta una situación pedagógica insostenible: la tendencia a evaluar el rendimiento escolar fundamentalmente por los niveles de información cultural de área. Sin que ello signifique que cualquier contenido sea puramente formal y sirva para alcanzar cualquier tipo de destreza, es posible afirmar que, aunque no con el mismo nivel de eficacia, desde el punto de vista pedagógico, con uno sólo de los temas 
culturales del programa que debe estudiar un alumno de secundaria, por ejemplo, se podrían poner en marcha las estrategias pedagógicas conducentes al logro de casi todos los objetivos educativos del programa, a excepción de la información cultural específica del área.

c) Incluso identificando conocimiento de la educación y conocimiento de áreas culturales, se puede entender que hay un determinado conocimiento de la educación, hablando de la enseñanza, que no es el conocimiento de las áreas culturales: el conocimiento de la transmisión de los conocimientos de esas áreas culturales. La educación tendría efectivamente como misión, por ejemplo, la transmisión de conocimiento acerca de la Historia. En este caso, que ese conocimiento sea fiable y válido es problema de los historiadores y de los investigadores de esa área cultural; el conocimiento de la educación para la enseñanza sería, en este caso, el conocimiento de las estrategias de intervención.

d) Atendiendo a lo anterior, es obvio que existe una competencia distinta para educar y enseñar que para conocer un área cultural específica. En efecto, los conocimientos teóricos, tecnológicos y práxicos que se constituyen en objetivos de instrucción en la enseñanza, no los crea el profesionaldelaeducación; sonlosinvestigadores de cada área cultural los que los crean. $\mathrm{Al}$ profesional de la educación le corresponde, con fundamento de elección técnica, decidir: si el educando puede aprenderlos; si son coherentes con la representación conceptual de la intervención educativa; si tienen fundamento teórico, tecnológico y práxico, según el caso, en el conocimiento de la educación para ser utilizados como instrumento de la educación; qué nivel de contenidos es adecuado en un caso concreto, cual es el método de enseñanza adecuado y qué destrezas, hábitos y actitudes, conocimientos y competencias educativas se pueden desarrollar con la enseñanza de ese conocimiento. Es decir, el profesional de la educación domina los conocimientos teóricos, tecnológicos y práxicos del área cultural que va a enseñar, al nivel suficiente para enseñarlos; pero, como profesional de la educación, domina el conocimiento de la educación que le permite justificar y explicar la conversión de esos conocimientos de un área cultural en objetivo o instrumento de la intervención pedagógica.

e) Desde el punto de vista de la competencia educativa, la clave del conocimiento que es válido para educar no está en el dominio de las áreas culturales, como si fuera el especialista de ese área cultural (artista, historiador, químico, $u$ otros), sino en el dominio de la competencia pedagógica que le capacita para ver y utilizar el contenido cultural como instrumento y meta de acción educativa en un caso concreto, de manera tal que ese contenido cultural sea utilizado como instrumento para desarrollar en cada educando el carácter y sentido propios del significado de 'educación'. El conocimiento de la educación capacita al profesional de la educación, por ejemplo, no sólo para establecer el valor educativo de un contenido cultural y participar en el proceso de decidir su conversión en fin o meta de un determinado nivel educativo, sino también para establecer programas de intervención ajustados a hechos y decisiones pedagógicas que hagan efectiva la meta propuesta.

Hablar de conocimiento de la educación no implica interrogarse directamente acerca de los saberes de las áreas culturales. Cuando hablamos de "el conocimiento de la educación", es más apropiado preguntarse por qué determinados conocimientos se constituyen en meta o instrumento de la acción educativa o por qué es educable la dimensión cognitiva del hombre. Y así como de los conocimientos de cada área cultural podrían hablarnos, según el caso y con propiedad, el historiador, el geógrafo, el matemático, el físico, el crítico de arte, etc., 
porque son especialistas en cada una de esas áreas culturales, no cabe duda que responder adecuadamente a si tal o cual contenido histórico, matemático, físico, artístico, etc., debe constituirse en el contenido de la acción educativa que realizamos con un determinado sujeto, o a cómo cultivar su sentido crítico, exige interrogarse acerca de la educación como objeto de conocimiento.

En el primer supuesto, los conocimientos -la historia, la matemática, la física, etc.- son el objeto científico de estudio; en los dos casos del segundo supuesto, la transmisión misma y la mejora de la capacidad de conocer se convierten en objeto específico de la reflexión científica en forma de Didáctica y de Pedagogía cognitiva, según el caso. $Y$ así las cosas, el conocimiento como objeto de educación exige la investigación de la educación, es decir, exige que la educación se convierta en objeto de conocimiento, bien como Pedagogía cognitiva o bien como Didáctica, respectivamente, pero, además de responder a por qué se produjo un determinado acontecimiento educativo y a cómo se puede lograr un determinado acontecimiento educativo, hay que responder, también, a cómo se justifica ese acontecimiento como acontecimiento educativo y esta es una cuestión que sólo se responde desde la Pedagogía por medio del conocimiento que tenemos del concepto de educación y del significado de 'educación'. Esa es la pregunta desde la Pedagogía, no por mejorar nuestro modo de conocer, ni por mejorar nuestro modo de enseñar, sino la pregunta por la educación misma desde conceptos con significación intrínseca al ámbito de conocimiento 'educación'. Conocer un área cultural no es enseñar, porque, como acabamos de ver, las competencias que se requieren en cada caso son distintas y enseñar no es educar, porque podemos afirmar que hay enseñanzas que no educan, con fundamento en el significado propio de esos términos.
Hay que asumir sin prejuicios que la pedagogía es conocimiento de la educación y este se obtiene de diversas formas, pero, en última instancia, ese conocimiento, por principio de significación, sólo es válido si sirve para educar; es decir, para transformar la información en conocimiento y este en educación, desde conceptos con significación intrínseca al ámbito de educación.

Por una parte, hay que saber en el sentido más amplio del término (sé qué, sé cómo y sé hacer); por otra parte, hay que enseñar (que implica otro tipo de saber distinto al de conocer las áreas de experiencia cultural; enseñar implica hacer saber a otro); $y$, por si eso fuera poco, además, hay que educar, que implica, no sólo saber y enseñar, sino también dominar el carácter y sentido propios del significado de 'educación', para aplicarlo a cada área experiencia cultural con la que educamos. Cuando abordamos el área de experiencia cultural con mentalidad pedagógica específica ${ }^{4}$ y con mirada pedagógica especializada, nuestra preocupación intelectual nos permite distinguir entre "saber Historia",

$4 \quad$ Al pedagogo le compete hacer la intervención pedagógica con mirada especializada, para tener visión crítica de su método $y$ de sus actos, y con mentalidad específica, para integrar la teoría en la práctica y resolver en la interacción el problema de educar. La mentalidad pedagógica es representación mental que hace el pedagogo de la acción de educar desde la perspectiva de la relación teoría-práctica; hace referencia a la capacidad de resolución de problemas que se le atribuye al conocimiento de la educación en cada corriente desde la perspectiva de la acción.

La mentalidad pedagógica es específica. No es general sobre la vida, sino sobre la educación como objeto cognoscible y realizable. Ni es una mentalidad filosófica de las cosmovisiones del mundo, de la vida y de los sentidos de vida posibles, ni debe confundirse con la mentalidad educativa que se ajusta a criterios de significado $y$ orientación formativa temporal de educar. La mentalidad pedagógica es mentalidad fundada en la educación como objeto de conocimiento y por tanto en el conocimiento de la educación.

La mirada pedagógica es la representación mental que hace el profesional de la educación de su actuación técnica, es decir, de su actuación en tanto que pedagógica; se corresponde con la visión crítica que tiene el pedagogo de su método y de sus actos fundada en principios de intervención y principios de educación.

La mirada pedagógica es, por tanto, especializada, está focalizada a los problemas de educación y la competencia técnica de mirarpedagógicamente depende del conocimiento de la educación que se ha adquirido. 
"enseñar Historia" y "educar con la Historia", entendida esta como una materia de área cultural que forma parte del currículo junto con otras y se ha convertido desde la Pedagogía en ámbito de educación.

El ámbito de educación, tal como se usa en este contexto de argumentación, no es un espacio físico, sino un concepto derivado de la valoración educativa del área de experiencia que utilizamos como instrumento y meta de educación. El ámbito de educación es resultado de la valoración educativa del área de experiencia que utilizamos para educar y por eso en el ámbito de educación se integran el significado de educación, los procesos de intervención, las dimensiones de intervención y las áreas de experiencia y las formas de expresión en cada acepción técnica de ámbito.

El ámbito de educación, que es siempre expresión del área cultural valorada como objeto e instrumento de educación integra los siguientes componentes: área de experiencia con la que vamos a educar, formas de expresión convenientes para educar con esa área, criterios de significado de educación reflejados en rasgos de carácter y sentido inherentes al significado de educar, dimensiones generales de intervención que vamos a utilizar en la educación, procesos de educación que deben seguirse y acepción técnica de ámbito. Integrar estos componentes es lo que hace el conocimiento de la educación con cada área cultural para hablar con propiedad conceptual de educar "con" un área cultural como concepto distinto de enseñar un área cultural y conocer un área cultural que forma parte del currículo.

Si no confundimos conocimiento de áreas culturales y conocimiento de la educación, ni es verdad que el profesor es un aprendiz de las áreas culturales que enseña, ni es verdad que necesariamente el que más Arte sabe es el que mejor lo enseña, ni es verdad que el que mejor domine una destreza es el que mejor enseña a otro a dominarla, a menos que, tautológicamente, digamos que la destreza que domina es la de enseñar, ni es verdad que, cuando se enseña, estamos utilizando siempre el contenido cultural como instrumento de logro del carácter y sentido propio del significado de educación, porque enseñar no es educar. Es objetivo de la pedagogía transformar la información en conocimiento y el conocimiento en educación, construyendo ámbitos de educación desde las diversas áreas culturales, y precisamente por eso podemos decir que a la pedagogía le corresponde valorar cada área cultural como educación y construirla como "ámbito de educación" (Touriñán, 2021; SI(e)TE, 2020).

Esto es así, porque cada una de esas actividades requiere distintas competencias y destrezas para su dominio, y la práctica y perfección en una de ellas no genera automáticamente el dominio de la otra. En rigor lógico, hay que aceptar que el conocimiento de la educación es, pues, un conocimiento especializado que permite al pedagogo explicar, interpretar $y$ decidir la intervención pedagógica adecuada al área cultural que es objeto de enseñanza y educación, según el caso.

\subsection{El concepto de educación se vincula nominalmente a criterio de finalidad en las actividades}

En el ámbito del conocimiento de la educación y desde la perspectiva de la actividad, se puede mantener que las actividades que realizamos no son las que determinan el significado real. Las mismas actividades que realizamos para educar se realizan para otras muchas cosas, de manera que las actividades no identifican la acción educativa. En la educación se enseña, se convive, se comunica y se cuida, pero educar no es cada una de esas cosas por separado, ni todas juntas: 
- $\quad$ Cualquier tipo de influencia no es educación, porque, en caso contrario, influir en una persona para que deje de hacer lo que tiene que hacer para educarse, sería también educación.

- $\quad$ El hecho de que cualquier tipo de influencia no sea educación, no anula ni invalida la posibilidad de transformar cualquier tipo de influencia en un proceso educativo. Nada impide lógicamente que el educando, por sí mismo y a partir de la experiencia que otros le comunican (proceso de autoeducación), o por medio de las experiencias que otros le comunican (procesos de heteroeducación), pueda analizar con criterio fundado en el conocimiento de la educación esa influencia negativa y transformarla en un proceso de influencia educativa. No es educativa la manipulación o transmitir como verdadero un conocimiento de un área cultural que la investigación teórica del área prueba como falso. Sin embargo, sí es educativo desenmascarar la manipulación y utilizar un conocimiento falso para probar su error y ejercitar las destrezas de uso de los criterios teóricos de prueba.

- $\quad$ El hecho de que cualquier tipo de influencia no sea educación, pero pueda transformarse en un proceso de influencia educativa, no anula ni invalida la posibilidad de obtener resultados educativos por medio de procesos de influencia no orientados exclusivamente a finalidades educativas (procesos informales).

Desde la perspectiva de las actividades, distinguir cualquier otro tipo de influencia e influencias educativas, exige la valoración pedagógica de diversos modos de conducta, atendiendo al criterio de finalidad. Convivir no es educar, porque hay convivencias que no se especifican y cualifican como educativas. Comunicar no es educar, porque la comunicación es siempre un proceso simbólico-físico cuya finalidad es elicitar el mensaje a que apunta el hablante y el hablante no apunta siempre a la educación.
Conocer un área cultural no es enseñar, porque el conocimiento puede estar separado de la acción y enseñar no es educar, porque podemos afirmar que hay enseñanzas que no educan, etc.

Desde la perspectiva de la finalidad, la educación es valor, porque la finalidad es un valor que se elige. Como valor, el objetivo fundamental de la educación, como tarea, es el desarrollo de destrezas, hábitos, actitudes y conocimientos que capacitan a las personas para elegir, comprometerse, decidir, realizar y relacionarse con los valores, porque de lo que se trata en la tarea es de construir experiencia axiológica. Desde esa misma perspectiva, el objetivo fundamental de la educación, como resultado, es la adquisición en el proceso educativo de un conjunto de conductas que capacitan al educando para elegir, comprometerse, decidir y realizar su proyecto personal de vida, utilizando la experiencia axiológica para dar respuesta, de acuerdo con la oportunidades, a las exigencias que se plantean en cada situación, porque, en definitiva, de lo que se trata, respecto del rendimiento, es de utilizar la experiencia axiológica como instrumento de construcción de uno mismo y de formación: es una actividad, en definitiva, orientada a construirse a uno mismo y reconocerse con el otro en un entorno cultural diverso de interacción, por medio de los valores.

Llegados a este punto, podemos decir que la actividad educativa es "educativa", porque tiene la finalidad de educar y ajusta el significado a los criterios de uso común del término, igual que cualquier otro objeto que se defina $y$ sea comprensible. Desde una perspectiva descriptiva o expositiva que tenga presente las actividades enunciadas anteriormente, la finalidad de la educación, es que el educando adquiera conocimientos, actitudes y destrezashabilidades-hábitos que lo capacitan, desde cada actividad para decidir y realizar sus proyectos, dando respuesta de acuerdo con 
las oportunidades a las exigencias que se le plantean en cada situación.

\subsection{Hay que ir más allá del uso común y más allá de las actividades que corresponden a la definición nominal}

El uso común del término educación nos ayuda a configurar el concepto, de manera que somos capaces de discernir entre lo que es educar y lo que parece y esto es importante, porque, es posible que determinadas actividades parezcan educación y sean otra cosa. El análisis de las actividades nos ayuda a precisar más; no sólo discernimos (conocemos su aspecto y configuración), sino que avanzamos hacia la definición de los rasgos propios de educación. Además de saber que algo es educación, hace falta poder decir qué es educación. Hay que saber lo que es una cosa a diferencia de otra que también 'es'. Hay que explicar cada uno de los rasgos de la fisonomía de la cosa. Entonces, no solo discernimos una cosa de su apariencia, lo que es, de lo que no es, sino que, además, circunscribimos con precisión los límites donde la educación empieza y termina, su perfil unitario. Los criterios de uso común del término y los criterios vinculados a las actividades nos permiten discernir y vincular la definición a la finalidad: el concepto de educación queda demarcado en la misma medida que se cumplan los criterios de uso común del término y se preserve la finalidad de educar (Touriñán, 2015 y 2014a).

Pero nada de lo anterior nos permite establecer con certeza cuáles sean las finalidades concretas que tienen que ser vinculadas a lo que es el producto de la educación y a la orientación formativa temporal de cada momento, ajustada a la condición humana individual, social, histórica y de especie. Además de discernir, conocer el aspecto, hay que definir los rasgos propios de la educación y hay que llegar a entenderlos en su funcionamiento, porque saber qué es educación es saber discernir, saber definir y entender el concepto. $Y$ esto exige ir más allá del criterio de uso común del término y del criterio de actividad como finalidad para entender los rasgos distintivos del carácter de la educación y del sentido de la educación que cualifican y determinan en cada acto educativo su significado real.

La etimología y la sinonimia constituyen el ámbito de las definiciones nominales. En el ámbito de las definiciones nominales somos capaces de alcanzar un saber que nos permite discernir. Incluso podemos llegar a profundizar sobre los usos estipulativos, descriptivos y programáticos de la definición general (Scheffler, 1970). Pero saber no es solo discernir; hay que llegar a definir realmente, buscando los rasgos que nos permiten distinguir, lo que es, de lo que no es. El uso común del término educación nos ayuda a configurar el concepto, de manera que somos capaces de discernir lo que es educar, de lo que parece.

El análisis de las actividades nos ayuda a precisar más: no sólo discernimos (conocemos su aspecto y configuración), sino que avanzamos hacia la definición de los rasgos propios de educación. Además de saber que algo es educación, hace falta poder decir qué es educación. Hay que saber lo que es una cosa a diferencia de otra que 'es' también. Pero el análisis de las actividades nos permite afirmar que las actividades que realizamos en educación no son las que determinan el significado real. Las mismas actividades que realizamos para educar se realizan para otras muchas tareas. Tenemos criterios de uso del término que nos permiten discernir, pero solo alcanzamos el espacio de la definición real, si nos adentramos en los rasgos que caracterizan la cosa a definir. El camino de la definición real se inicia en el análisis de las actividades que nos permite preservar la finalidad, pero va más allá. 
En el contexto de la educación, la práctica totalidad de las definiciones del término se mueven entre la definición nominal (etimológica o sinonímica) y la vinculación a la finalidad de los usos del término. Es una práctica frecuente definir partiendo de las definiciones previas dadas por otros autores y extractar los rasgos que mejor se ajustan a la posición particular del contexto que queremos defender, como si fueran definiciones expositivas o descriptivas. Muy diversos trabajos recopilan múltiples definiciones de educación que se ajustan a esta forma de definir (Sáez, 2007; García Aretio, Ruiz Corbella y García Blanco, 2009).

Sin embargo, este modo de actuar ha dado lugar, unas veces, a un excesivo formalismo en el contexto de la definición, porque, a fuerza de buscar los significados de uso común que sean aceptados de manera general, estas definiciones no se comprometen con las situaciones concretas no comunes y evitan entrar en relación con los usos previos, en particular. En otras ocasiones, dado que estas definiciones no tratan de conciliar o confrontar las doctrinas de las múltiples corrientes en torno los diversos significados recopilados, sino que buscan destacar los rasgos que se consideran denotativos y configuradores del concepto, la definición acaba con frecuencia en un despreocupado eclecticismo (Quintana, 1988, p. 51; Berlo, 1979, pp. 209-228). Si educar es transformar la animalidad en humanidad, ¿cuántas maneras tenemos de hacerlo?; si educar es dar al cuerpo y al alma toda la perfección de que son susceptibles, ¿cómo identificamos, discernimos, definimos, creamos o desarrollamos esa perfección?; si la educación es perfeccionamiento intencional de las capacidades específicamente humanas, ¿son humanas todas las capacidades del hombre o hay algunas que son del hombre y no son humanas $\mathrm{y}$, por tanto, no tendrían que ver con la educación?
Tenemos que ir más allá de la definición nominal: además de discernir, conocer el aspecto, hay que definir los rasgos propios de la educación y hay que llegar a entenderlos en su funcionamiento. $Y$ esto exige ir más allá del criterio de uso común del término y del criterio de actividad como finalidad para entender los rasgos distintivos del carácter de la educación y del sentido de la educación que cualifican y determinan en cada acto educativo su significado real. Pero, lo cierto es que, una buena parte del pensamiento pedagógico, en lugar de seguir este camino, se ha inclinado, por costumbre, hacia el pensamiento metafórico, compatible con el pensamiento pedagógico antinómico (Mantovani, 1972).

El paso de la definición nominal a la definición real exige descubrir los rasgos propios de la educación y entenderlos en su funcionamiento. Hay que explicar cada uno de los rasgos de la fisonomía de la cosa definida. Entonces, no solo discernimos una cosa de su apariencia, lo que es de lo que no es, sino que, además, circunscribimos con precisión los límites donde la educación empieza y termina, su perfil unitario, porque saber qué es educación no es solo saber discernir, sino también saber definir y entender el concepto.

Tenemos que llegar a la definición real, porque la verdad de cada cosa definible se funda en el ser mismo de ella, en los rasgos que le son propios y la justifican como tales, porque le confieren carácter y sentido, determinación y cualificación, frente a cualquier otra cosa que es y tiene las propiedades que le pertenecen por necesidad lógica. Entender no es solo ver el conjunto de rasgos que se ofrecen a quien contempla, sino justificarlos como rasgos que previamente constituyen la cosa en cuestión; hay que entender por qué esa cosa es así y no de otra manera. Al saber las cosas de este modo, sabemos la necesidad de que sean como son y, por tanto, por qué no son de otro modo. 
Al definir rasgos y entenderlos, sabemos en sentido pleno: 1) demostramos la necesidad lógica de unos caracteres o rasgos constitutivos, 2) razonamos teórica y prácticamente sobre sus principios y 3) calibramos la impresión de realidad que nos trasmiten (Zubiri, 1978, pp. 3944).

Saber en sentido pleno es conocimiento con coherencia y sentido crítico. Es un saber próximo a la sabiduría que siempre requiere integración personal de lo sabido. Asumir la competencia de saber en sentido pleno ha obligado a pensar en nuevas revisiones en el ámbito de la investigación de nuevos procesos y entornos de adquisición de conocimiento que se configuran como entornos personales de aprendizaje (Reig, 2012), compatibles con trayectorias personales de aprendizaje que orientan nuevas teorías de la enseñanza (Stzajn, Confrey, Wilson y Edington, 2012) y que sirven para crear fondos de conocimiento personal (González, Moll, y Amanti, 2005). Son aprendizajes específicos que afectan a la capacidad cognitiva, al procesamiento de la información y a la competencia socio y afectivoemocional, en la perspectiva del aprendizaje situado y significativo (Novak, 1998; Díaz Barriga, 2006; Polanyi, 1978; Ausubel, 1982).

Nada de la definición nominal nos permite establecer con certeza cuáles sean las finalidades concretas que tienen que ser vinculadas a lo que es el producto de la educación y a la orientación formativa temporal de cada momento, ajustada a la condición humana individual, social, histórica y de especie. Tampoco sabemos con exactitud desde la definición nominal cuales son los componentes estructurales de la intervención pedagógica, porque aquella no nos adentra en la complejidad objetual de la educación. Nada nos dice la definición nominal sobre la capacidad de resolver problemas teóricos y prácticos de la acción educativa, porque no nos adentra en la capacidad de resolución de problemas del conocimiento de la educación. Ninguna de esas cuestiones es asunto simplemente deducible de manera directa desde la idea de finalidad. Tenemos que construir la definición real. Y eso significa responder a una doble pregunta fundamentante: qué tienen en común todas las actividades para que sea posible educar y cuáles son esos rasgos inherentes al significado de educar.

Desde la perspectiva de la definición real, distinguir cualquier otro tipo de influencia e influencias educativas, exige la valoración pedagógica de diversos modos de conducta, atendiendo no solo a criterios de uso y finalidad, sino también entender la actividad como estado y capacidad común que hace posible que el hombre se eduque y además atender a criterios de significado intrínsecos al propio concepto de educación para que se puedan construir principios de educación y de intervención pedagógica por medio del conocimiento de la educación. En definitiva, hemos de construir el pensamiento que nos permita justificar que la actividad educativa es "educativa", porque: 1) se ajusta a los criterios de uso del término, 2) cumple la finalidad de educar en sus actividades y 3) se ajusta al significado real de esa acción, es decir se ajusta a los rasgos de carácter y sentido que le son propios, igual que cualquier otra entidad que se defina y sea comprensible.

Pero, para poder afirmar que algo es realmente educativo y es educación, tenemos que preguntarnos:

- $\quad$ Qué hacemos con todas las actividades para que se conviertan en educación

- Qué hacemos para que una actividad artística sea educativa

- $\quad$ Que hacemos para que un determinado contenido de área cultural sea transformado de información en conocimiento y de conocimiento en educación 
- $\quad$ Que hacemos para que, en unos casos, enseñemos un área cultural y, en otros casos, eduquemos con el área cultural

- Que hacemos para transformar un área de experiencia cultural en un ámbito de educación

- Qué hacemos para construir un ámbito educativo integrado en la arquitectura curricular

Tenemos que avanzar desde discernir, conocer el aspecto, a definir los rasgos propios de educación y a entenderlos en su funcionamiento, porque saber qué es educación es discernir, definir y entender. Todas las educaciones especificadas (matemática, ambiental, intelectual, física, afectiva, profesional, virtual, etc.), son educaciones, porque todas ellas son, genéricamente, educación y eso quiere decir que tienen en común los rasgos propios que determinan y cualifican una acción como educación y, en cada caso se ejecuta como acción educativa concreta y programada que tiene en cuenta todos y cada uno de los elementos estructurales de la intervención pedagógica.

Desde el punto de vista de la definición real, "educar" exige hablar de educación, atendiendo a rasgos distintivos del carácter de la educación y del sentido de la educación que determinan y cualifican en cada acto educativo su significado real. Educar es realizar el significado de la educación en cualquier ámbito educativo, desarrollando las dimensiones generales de intervención y las competencias adecuadas, las capacidades específicas y las disposiciones básicas de cada educando para el logro de conocimientos, actitudes y destrezashabilidades-hábitos relativos a las finalidades de la educación y a los valores guía derivados de las mismas en cada actividad interna y externa del educando, utilizando para ello los medios internos y externos convenientes a cada actividad, de acuerdo con las oportunidades (Touriñán, 2014b, 2015).

Desde el punto de vista de la definición real de educación, tenemos que avanzar en el conocimiento de todos estos rasgos distintivos y tiene sentido preguntarse dónde está la educación y cómo llegamos al conocimiento de sus rasgos distintivos, porque hay que ir más allá de la etimología, de la sinonimia y de la finalidad, para alcanzar el significado real y poder establecer principios de educación vinculados al carácter y al sentido inherentes al significado de educación y principios de intervención vinculados a los elementos estructurales de la intervención, atendiendo a lo común de la actividad.

Principios de educación y principios de intervención pedagógica no son lo mismo. Los principios de intervención pedagógica derivan de los elementos estructurales de la intervención (conocimiento de la educación, función y profesión pedagógica, relación educativa, agentes de la educación, procesos, productos y medios). Los principios de educación nacen vinculados al carácter y al sentido que son inherentes al significado de 'educación'. El carácter propio del significado de 'educación' proviene, como vamos s ver en los epígrafes siguientes, de la complejidad objetual de 'educación' y la complejidad objetual, que nace de la propia diversidad de la actividad del hombre en la acción educativa, puede sistematizarse desde los ejes que determinan los rasgos de carácter de la educación. El sentido, que pertenece al significado de 'educación', se infiere de la vinculación entre el yo, el otro y lo otro en cada acto educativo y cualifica el significado, atendiendo a categorías conceptuales de espacio, tiempo, género y diferencia específica. Desde la perspectiva del carácter y del sentido, se dice que toda acción educativa es de carácter axiológico, personal, patrimonial, integral, gnoseológico y espiritual y que toda acción educativa tiene, al mismo 
tiempo, sentido territorial, durable, cultural y formativo. Justamente porque se puede desarrollar un sistema conceptual en educación basado en su definición real, la Pedagogía desarrolla principios de educación, ajustados a los rasgos de carácter y sentido de educación, y principios de intervención, ajustados a los elementos estructurales de la intervención. Los principios de educación, derivados del carácter y del sentido de la educación, fundamentan las finalidades educativas. Los principios de intervención fundamentan la acción. Ambos principios tienen su lugar propio en la realización de la acción educativa controlada.

La visión crítica que el pedagogo tiene de su actuación en tanto que pedagógica, es una visión ajustada a los elementos estructurales de la intervención, que son los cuatro componentes estructurales de intervención vinculados a la mentalidad (conocimiento, función, profesión y relación) y los cuatro componentes estructurales de la intervención vinculados a la acción en tanto que acción (agentes, procesos, productos y medios). En cada intervención vinculamos mentalidad pedagógica específica, mirada pedagógica especializada y acción porque nos ajustamos a esos ocho elementos estructurales atendiendo a principios de intervención y a principios de educación (Touriñán, 2016).

Desde la perspectiva de los elementos estructurales de la intervención pedagógica se dice que la intervención obedece a principios de realidad y normatividad, de especificidad, especialización y competencia, de autoridad institucionalizada, de libertad compasiva, de actividad controlada, de dirección temporal, de significado y finalidad y de oportunidad organizativa.

Desde la perspectiva de los rasgos de carácter y sentido inherentes al significado de educación, se dice que la educación obedece a principios de integración cognitivo-comprensiva (comprensión), de integración afectivo- expresiva (positividad), de originalidad y compromiso (autenticidad), de responsabilidad y sentido de acción (coherencia), de identidad, individualización y sentido de vida (idoneidad), de integración creativa (interpretación de símbolos), de socialización, de progresividad, de diversidad y diferenciación y de interés.

Así mismo, desde la perspectiva de los rasgos de carácter y sentido pedagógico que determinan y cualifican el significado de educación, se infieren las finalidades intrínsecas, autóctonas, que denominamos con rigor lógico, metas pedagógicas de sabiduría, felicidad, determinación, libertad, autonomía, salud física y mental, convivencia, perfeccionamiento, instrucción y formación (Touriñán, 2017).

Este razonamiento nos sitúa ante el reto de ir más allá de la definición nominal y de la actividad con finalidad: además de discernir (conocer el aspecto), hay que definir los rasgos propios de la educación y hay que llegar a entenderlos en su funcionamiento. $Y$ esto exige ir más allá del criterio de uso común del término y del criterio de actividad como finalidad para centrarse en lo que la actividad tiene de común como capacidad para educar y en los rasgos distintivos del carácter de la educación y del sentido de la educación que cualifican y determinan en cada acto educativo su significado realmente. Vamos a avanzar en este reto afrontando dos cuestiones: 1) el análisis de la actividad como capacidad, desde la perspectiva de la función pedagógica y 2) la sistematización de los rasgos de carácter y sentido de la educación que determinan y cualifican su significado.

\section{LA FUNCIÓN PEDAGÓGICA GENERA INTERVENCIÓN DESDE LAS ACTIVIDADES COMUNES}

En educación realizamos muchas acciones con el objeto de influir en el educando y lograr el resultado educativo. Son siempre acciones mediadas de un sujeto con otro o de un sujeto consigo mismo. $Y$ todas esas acciones, que 
tienen que respetar la condición de agente del educando, buscan provocar la actividad del educando. En su uso más común, 'actividad' se entiende como estado de actividad, es actividad-estado: la actividad es el estado en que se encuentra cualquier persona animal o cosa que se mueve, trabaja o ejecuta una acción en el momento en que lo está haciendo (decimos: este niño está pensando). Este uso hace referencia también a la capacidad que tenemos de acción en esa actividad y por eso decimos este niño ha perdido actividad (ahora piensa menos, ha dado un bajón). Por ser el uso más común del término 'actividad' como estado y capacidad, lo denominamos actividad común y se da en todas las personas porque en todas las personas hay actividad como estado y como capacidad de hacer (Touriñán, 2014a y 2020a).

Respecto de la actividad común, hemos de decir que la investigación actual distingue entre acciones ejecutadas para obtener un resultado y acciones cuyo resultado es la propia acción. Así, por ejemplo, la acción de resolver un problema tiene por resultado algo "externo" a la acción: obtener una solución (estudiar tiene como resultado dominar un tema;). En todos estos casos, no se puede ejecutar la acción de resolver el problema y tenerlo resuelto. Sin embargo, no puedo sentir sin estar sintiendo, pensar sin estar pensando, proyectar sin estar proyectando, etc. Las primeras son actividades externas y las segundas son actividades internas. Nosotros, desde ahora, hablaremos respecto de la educación, de actividad común (actividad estado y capacidad) interna (resultado es la propia acción: pensar, sentir, querer, operar, proyectar y crear) y externa (actividad estado y capacidad, cuyo resultado es externo a la propia acción, pero vinculado conceptualmente a la actividad en sí: tengo capacidad lúdica, tengo capacidad de estudiar, tengo capacidad de trabajar, de intervenir, de indagar-explorar y tengo capacidad de relacionar).
Desde la perspectiva de la actividad común interna podemos hacer una taxonomía de las actividades tomando como referente el agente educando. Todos convenimos en que, cuando nos educamos, sea auto o heteroeducación, nuestra condición humana nos permite realizar las siguientes actividades comunes internas: pensar, sentir afectivamente (tener sentimientos), querer objetos o sujetos de cualquier condición, operar (elegir-hacer cosas procesando medios y fines), proyectar (decidiractuar sobre la realidad interna y externa orientándose) y crear (construir algo desde algo, no desde la nada, simbolizando la notación de signos: darse cuenta de algo -notar- y darle significado -significar-, construyendo símbolos de nuestra cultura). Nadie se educa sin estar pensando, sintiendo, queriendo, etc. Educarse es mejorar siempre esa actividad común interna y saber usarla para actividades especificadas instrumentales que nos hacen ser cada vez más capaces de decidir y realizar nuestros proyectos.

También convenimos en que, cuando nos educamos, nuestra condición humana nos permite realizar las siguientes actividades comunes externas: juego, trabajo, estudio, intervención, indagación-exploración y relación (de amigo, familiar, de pareja, social, etc.). Son actividades comunes (estado y capacidad), porque tengo capacidad para el estudio, el juego el trabajo, la exploración, la intervención y la relación. $Y$ son actividades comunes externas, porque tienen necesariamente un resultado a obtener, que es externo a la actividad en sí, pero que está vinculado conceptualmente como meta a la actividad y la caracteriza como rasgo identitario. De ahí que digamos que estudiar es disponer y organizar información escrita "para" su dominio (dominar o saber el tema de estudio); el dominio-saber del tema de estudio es el resultado externo de la actividad $y$ ese resultado es la finalidad que identifica el estudio, con independencia de que yo pueda utilizar el estudio para hacer un amigo, 
para ayudar altruistamente a otro, para robar mejor, etcétera, que son usos de la actividad como especificaciones instrumentales de ella (Touriñán, 2016).

Como actividad común externa, estudiar, por ejemplo, tiene un fin propio vinculado a esa actividad de manera conceptual y lógica (el fin propio de estudiar es dominar-saber aquello que se estudia: una información, un contenido o la propia técnica de estudio). Pero, además, como actividad común externa, estudiar puede convertirse en actividad instrumental especificada para otras finalidades, son finalidades especificadas y externas a la actividad en sí, pero vinculadas a la actividad de estudiar de manera empírica o experiencial (estudiar se convierte en actividad instrumental especificada, porque podemos estudiar para robar, para hacer amigos, para ayudar a otro, para educarse, etcétera) (Touriñán, 2019a).

Es un hecho que las actividades comunes se usan propedéuticamente para finalidades educativas, pero también pueden usarse para otras finalidades. Las actividades comunes pueden ser usadas para realizar actividades especificadas instrumentales y tienen valor propedéutico; son preparatorias para algo posterior. $Y$ esto es así, por una parte, porque todo lo que usamos como medio en una relación medio-fin, adquiere la condición propia de los medios en la relación (el medio es lo que hacemos para lograr el fin y el fin es un valor elegido como meta en la relación medios-fines) $y$, por otra parte, es así, porque el medio muestra su valor pedagógico en las condiciones que le son propias, ajustando el medio al agente, a la finalidad educativa y a la acción, en cada circunstancia (Touriñán, 2020b).

Desde la perspectiva de la actividad común interna podemos decir que la actividad es principio de la educación, porque nadie se educa sin estar pensando, sintiendo, queriendo, etc. $Y$ desde el punto de vista de la actividad común externa podemos decir que hacemos muchas actividades cuya finalidad es 'educar'. Siempre, desde la perspectiva del principio de actividad como eje directriz de la educación: educamos con la actividad respetando la condición de agente (Touriñán, 2015).

Si esto es así, se sigue que los medios tienen que ajustarse a la actividad del sujeto $\mathrm{y}$ al significado de educación. Son medios para un sujeto concreto que piensa, siente, quiere, opera, proyecta y crea. Son medios para realizar actividad, jugando, trabajando, estudiando, indagando, interviniendo y relacionándose. Pero el agente realiza esas actividades para educarse: no piensa de cualquier manera, sino de la que se va construyendo para educarse y actuar educadamente, y así sucesivamente con todas las actividades. Se sigue, por tanto, que cualquier medio no es 'el medio' para un sujeto concreto; en la acción educativa, el sujetoeducando actúa con los medios internos que tiene y con los medios externos que han sido puestos a su disposición. $Y$ todos esos medios solo son medios educativos, si sirven para educar a ese sujeto-educando. Los medios no son exactamente los mismos, si quiero formar el sentido crítico, o si quiero educar la voluntad para producir fortaleza de ánimo. Precisamente por eso se explica la tendencia a centrarse en los medios específicos y particulares de una acción, olvidándose de los medios comunes y compartidos con otras actividades educativas.

La actividad está presente en toda educación: desde una perspectiva, como principio de intervención y, desde otra, como principio de educación. $Y$ precisamente por ser esto así, se explica que la actividad se convierta en el principio-eje vertebrador de la educación y represente el sentido real de la educación como actividad dirigida al uso y construcción de experiencia valiosa para generar actividad educada. Usamos la actividad común para educar, educamos las competencias adecuadas 
de la actividad común y esperamos obtener actividad educada. En definitiva, usamos la actividad de manera controlada para lograr actividad educada y educar la actividad por medio de las competencias adecuadas (Touriñán, 2016).

El principio de actividad, ni es pasividad, ni es activismo; es uso de la actividad de manera controlada para actuar educadamente. Y de este modo, la actividad y el control son principios de la intervención pedagógica, derivados de la condición de agente que tiene que construirse a sí mismo y reconocerse con el otro y lo otro en un entorno cultural diverso de interacción, por medio de los valores que ha de elegir, comprometerse, decidir y realizar, ejecutando por medio de la acción concreta lo comprendido e interpretado de la relación medio-fin, expresándolo, de acuerdo con las oportunidades.

Esto es así, porque, por principio de actividad, nadie se educa sin estar pensando, sintiendo, queriendo, pensando, operando, proyectando y sin estar interpretando símbolos de nuestra cultura creativamente. Nos educamos con la actividad común interna. Pero, además, nos educamos por medio de la actividad común externa (estudiando, jugando, trabajando, indagando-explorando, interviniendo $\mathrm{y}$ relacionándonos con el yo, el otro y lo otro), porque al ejercer una concreta actividad común externa activamos las capacidades comunes internas, las entrenamos, las ejercitamos, las ejercemos y las mejoramos para hacer bien cada actividad común externa. La actividad común externa, por principio de actividad, activa la actividad común interna en cada ejecución concreta de la actividad común externa, sea esta jugar, estudiar, trabajar, indagar, intervenir o relacionar. Al ejecutar la actividad común externa, mejoramos y entrenamos las actividades-capacidades internas: $\sin$ la actividad es imposible educar y gracias a ella se hace posible que el educando sea agente actor y cada vez mejor agente autor de su propios proyectos y actos.

El principio de actividad permite afirmar en Pedagogía que la actividad común externa (por ejemplo, jugar) activa la actividad común interna de pensar, sentir, querer, operar, proyectar y crear, pero eso no significa caer en el activismo: la actividad por la actividad no educa; pensar de cualquier manera no es educarse, pues educarse, como mínimo, requiere que, al pensar, se mejore el hábito y el modo de pensar.

Por todo eso, la educación es un problema de todos y todos contribuimos a ella porque todos nos formamos y tenemos que usar la actividad común para educar y educarnos y sin ella no es posible hacerlo.

\section{COMPLEJIDAD OBJETUAL $Y$ CARÁCTER DE LA EDUCACIÓN: UNA EXIGENCIA INSOSLAYABLE EN LA DEFINICIÓN REAL}

En el ámbito de la metodología de investigación hay un principio básico: el principio de correspondencia objetual. El método depende del objeto o del aspecto de la realidad que se pretende conocer. Directa e indirectamente, la investigación pedagógica ha avanzado asumiendo que la correspondencia objetual es una condición de la metodología: el método debe adecuarse a los objetos que investiga (González Álvarez, 1947). La correspondencia objetual quiere decir que el método depende del objeto o del aspecto de la realidad que se pretende conocer $\mathrm{y}$, por consiguiente, tan cierto es que no se puede formular el método con anterioridad a emprender el estudio del objeto, porque un método descrito a priori suele ser inadecuado al objeto, como que tampoco se puede llegar lejos en el estudio del objeto sin adquirir un método, porque se procederá de modo desorganizado (Colbert, 1969, p. 667). Estamos obligados metodológicamente por el principio de correspondencia objetual a 
avanzar en el desarrollo teórico del objeto de investigación.

En el año 1947 el profesor González Álvarez, enunció este principio fundamental de la metodología: "toda ciencia, como producto humano que es, depende de dos factores fundamentales: el objeto sobre el que versa y el sujeto que la elabora. Ello implica esta verdad fundamental: el método de una disciplina debe ser congruente con la estructura noética del objeto que investiga y adaptado a la contextura cognoscitiva del sujeto que la recibe" (González Álvarez, 1947, p. 10). Esta afirmación nos confirma, por una parte, que cualquier método no sirve para cualquier investigación y, por otra, la necesidad de adaptarse a las condiciones bajo las cuales la verdad se nos ofrezca. En el caso de la relación educativa, es preciso entender que la relación solo se singulariza, si se tiene en cuenta la complejidad del objeto educación y se asumen los rasgos de carácter que determinan una acción singular y concreta como 'educación'.

\subsection{La complejidad objetual se vincula} a la actividad común interna del agente y determina los rasgos de carácter de 'educación'

La investigación pedagógica, tiene que atender al objeto de conocimiento que le es propio: la educación. $Y$ en este empeño, estamos abocados a la complejidad por la propia condición del objeto 'educación', porque, muy diversos aspectos hacen de la educación un objeto complejo y el paradigma de la complejidad ayuda a perfilar las condiciones que lo hacen así (Arendt, 1974; Ballester y Colom, 2017; Lyotard, 1984; Prigogine, 1997; Prigogine y Stengers, 1983; Lipovetsky, 1986; Touriñán y Sáez, 2006 y 2012; Luhman, 1983; Maslow, 1982; Bateson, 1979; Damasio, 2010; Pinker, 2003; Zubiri, 2006).
El desplazamiento que se ha operado en la epistemología actualmente señala con claridad que lo esencial no consiste en eliminar las interpretaciones perspectivistas, sino en "la elaboración de un modo de conocimiento totalmente crítico, es decir, que sea capaz de controlar cada uno de sus procesos, de proponerse conscientemente sus metas y de autojustificar los procedimientos que utiliza para conseguirlos" (Ladriere, 1977, p. 115). Un conocimiento objetivo debe poder juzgarse $y$, por tanto, tiene que "pronunciarse sobre el valor y los límites de validez de lo que al final propone" (Ladriere, 1977, p. 115).

La variación que se ha operado apunta al aparato conceptual interpretativo y sus reglas de racionalidad no están dadas 'a priori': "La crítica asocia, además, de modo inseparable, el juicio y la elaboración de los criterios de juicio. No posee de antemano los principios según los cuales podrá dirigir sus apreciaciones; construye sus principios a medida que los utiliza (...) las normas implícitas de la ciencia no existen 'a priori', se construyen y reconstruyen continuamente" (Ladriere, 1977, p.115).

La idea de dominio es, según Ladriere, la que resume quizás de modo mejor lo específico de este cambio hacia lo complejo desde el concepto de objetividad; el dominio "representa la capacidad de alcanzar con seguridad los objetivos que se propone y de independizarse de todos los condicionamientos exteriores" (Ladriere, 1977, p. 120). La racionalidad de los medios exige la racionalidad de los objetivos marcados, porque no es suficiente garantía de conocimiento decir que se hace lo que los "científicos normalmente hacen"; la correspondencia objetual debe estar siempre presente en cada acción metodológica.

Si queremos abordar la sustantividad propia de la acción educativa en su totalidad, el conocimiento de la educación está abocado, por desarrollo de la metodología, hacia paradigmas críticos y de 
la complejidad y, por evolución del concepto de objetividad, hacia posturas comprensivas que reconocen el carácter axiológico de los hechos y la condición fáctica del valor. Estamos abocados a la complejidad por la propia condición del objeto 'educación'.

La idea de simplicidad que ha presidido siempre la metodología de investigación no es contradictoria con la idea de paradigmas de la complejidad. Simplicidad no significa renunciar a explicar un ámbito en conceptos nuevos o reducir su explicación a lo que sea posible desde los conceptos de otras ciencias. La simplicidad no se considera un principio irrefutable, y ciertamente no es un resultado científico, porque la explicación más simple y suficiente es la más probable, mas no necesariamente la verdadera. Su sentido básico es que, en condiciones idénticas, serán preferidas las teorías más simples, pero es una cuestión diferente cuales serán las evidencias que apoyen la teoría. En contra del principio de simplicidad, el sentido común nos dicta que una teoría más simple pero menos correcta no debería ser preferida a una teoría más compleja pero más correcta (Novak, 1998; Bunge, 1975, pp. 145-184). Así las cosas, a menos que se defienda erróneamente que no queremos obtener nuevos conocimientos, o que el conocimiento ha llegado a un grado de perfección tal que no puede mejorarse, hay que reconocer que son las teorías mismas con las que nos enfrentamos a la realidad las que nos fuerzan a valorar o despreciar datos. No es que no existan datos; más precisamente lo que ocurre es que nos sentimos en condiciones de no prestarles atención.

El profesor Colom, que ha dedicado muy diversos trabajos al problema de la complejidad del objeto de conocimiento 'educación', resume su posición sobre la complejidad de la educación en su trabajo "Pedagogía del laberinto" y nos dice que 'educación' es un objeto complejo, porque (Colom, 2008, p.10):
- La educación integra al niño, pero este tendrá que reestructurar lo recibido

- Las influencias educativas de distintos ambientes no se desarrollan en el mismo sentido y hacen imprevisibles la evolución y el desarrollo

- $\quad$ El punto de partida es diferente para cada educando y la materia educativa es impartida por sujetos diferentes

- $\quad$ El currículum que sirve para ordenar la enseñanza y el aprendizaje da lugar a prácticas diversas, con lo cual el orden de la educación da lugar a la diferenciación

- El fracaso escolar evidencia que el sistema educativo no es tan ordenado y previsible como parece.

Por su parte, Edgar Morin nos dice que conducir a la humanidad al saber de sus "propias realidades complejas" es posible (Morin, 2009, p. 18) y mantiene que el conocimiento de lo humano es complejo, porque (Morin, 2009, p. 17):

- $\quad$ Su campo de observación y de reflexión es un laboratorio muy extenso

- Reconoce que el sujeto humano que estudia está incluido en su objeto

- $\quad$ Concibe inseparablemente unidad y diversidad humanas

- Concibe relacionadas todas las dimensiones o aspectos que actualmente están disjuntos y compartimentados en los estudios del hombre

- Mantiene juntas verdades disjuntas que se excluyen entre sí

- $\quad$ Alía la dimensión científica (verificación, hipótesis, refutabilidad) a las dimensiones epistemológica y filosófica 
- $\quad$ El conocimiento debe ser a la vez mucho más científico, mucho más filosófico y en fin mucho más poético de lo que es

- Hay que encontrar sentido a las palabras perdidas y despreciadas por las ciencias, incluidas las cognitivas: alma, mente, pensamiento.

Para Morin, la educación asume la complejidad de lo humano en la acción educativa. La acción educativa es compleja, porque, en ella, los educandos junto con los educadores encuentran posibilidades de autoconstrucción de su autonomía (Morin, 2009, p. 312):

- A través de la capacidad de adquirir, capitalizar, explotar la experiencia personal

- A través de la capacidad de elaborar estrategias de conocimiento y comportamiento (es decir, dar la cara a la incertidumbre)

- A través de la capacidad de elegir y modificar la elección

- $\quad$ A través de la capacidad de consciencia.

Para mí, la complejidad del objeto de conocimiento 'educación' nace de la propia diversidad de la actividad del hombre en la acción educativa, tanto que hablemos de las competencias adecuadas para educar (talento, talante, tesón, temple, trayectoria personal y tono vital creador), como si hablamos, en relación con la educación, de actividad común (actividad como estado y capacidad) interna y externa y de actividad especificada (actividad como tarea con finalidad). Esto es así, porque, cuando educamos, buscamos siempre competencia para elegir, obligarse, decidir y sentir valores realizados y realizables como educativos y todo ello exige integración cognitiva e integración creativa. Se exige integración cognitiva, porque en cada acción hay que relacionar ideas y creencias con las expectativas y convicciones, utilizando las formas de pensar para articular valores pensados y valores creídos con la realidad por medio del conocimiento y la racionalidad. Se exige integración creativa, porque en cada acción hay que articular valor y creaciones, vinculando lo físico y lo mental para construir cultura simbolizando; la integración creativa es forma de relación creadora entre el yo, el otro y lo otro y consecuencia emergente de la vinculación humana entre lo físico y lo mental en el cerebro que hace posible crear cultura y símbolos para notar y significar la realidad y dar respuesta desde nuestros proyectos a la condición humana individual, social, histórica y de especie (Touriñán, 2016).

Para todo eso, en la educación, unas veces nos centramos en la inteligencia, otras en los sentimientos, otras en la voluntad, otras en la intencionalidad, otras en la moralidad y otras en la sensibilidad espiritual creadora, de manera que se haga efectiva la generación de símbolos propios de la cultura humana. Y, por supuesto, para todo ello usamos recursos, y esos recursos son, en muchas ocasiones, los contenidos de las áreas de experiencia, pero, en tal caso, distinguiendo entre saber historia, enseñar historia y educar con la historia, por ejemplo.

Todo eso es la complejidad objetual de 'educación' que tiene que transformarse en acción educativa concreta, en cada caso de intervención. La complejidad nace de la diversidad de la actividad; intervenimos por medio de la actividad para lograr actividad educada y esto quiere decir que pasamos del conocimiento a la acción para formar la condición humana individual, social, histórica y de especie, atendiendo a las características propias del objeto 'educación', que hacen posible identificar sus rasgos internos determinantes (de carácter). La actividad es el pilar central de la complejidad del objeto 'educación'

La complejidad objetual es la propiedad de la investigación pedagógica que nos hace mantener con realismo la vinculación de la 
condición humana individual, social, histórica y de especie con el objeto 'educación', y atender a las características propias de este, cuyas relaciones hacen posible identificar sus rasgos internos determinantes (de carácter) y afrontar cada intervención como conocimiento y acción y como vinculación entre valor, elección, obligación, decisión, sentimiento, pensamiento y creación. Las relaciones que se establecen entre esos elementos hacen posible identificar los rasgos internos determinantes (de carácter) de la educación. El carácter es el rasgo distintivo o conjunto de características que determinan a algo como lo que es. El carácter de la educación es su determinación, lo que la determina y eso que la determina nace de la complejidad objetual de educación que exige resolver en cada caso concreto de actuación las relaciones entre valor, elección, obligación, decisión, sentimiento, pensamiento y creación que son propias de la actividad común interna del hombre y quedan reflejadas en el Cuadro 1.

Cuadro 1: Complejidad objetual de 'educación'

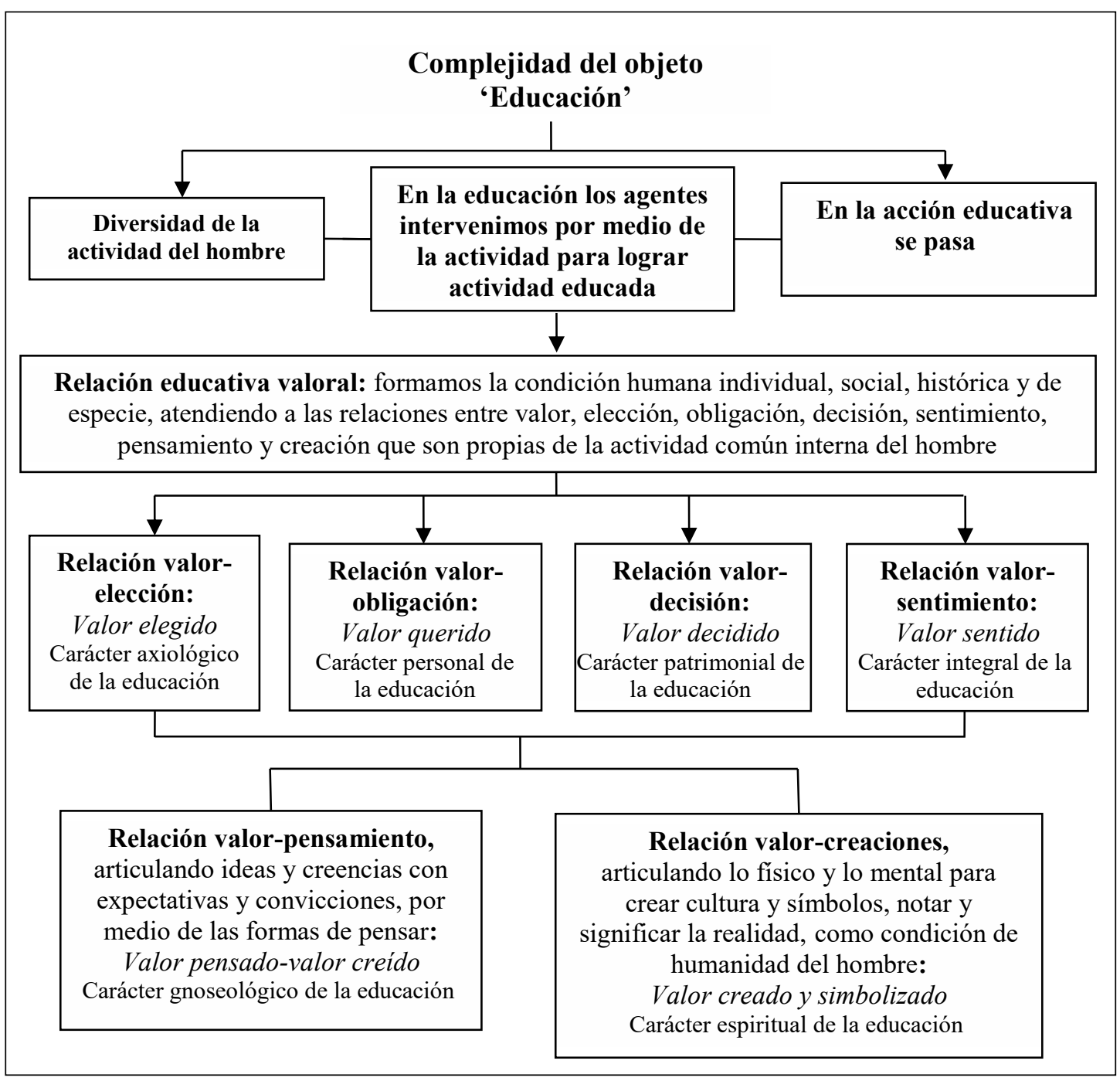

Fuente: Touriñán, 2014a, p. 352 
Esto es así, porque la actividad común interna de cualquier humano que se educa implica pensar, sentir afectivamente (tener sentimientos), querer objetos o sujetos de cualquier condición, operar ("elegir hacer" cosas, construyendo procesos, procesando medios y fines), proyectar ("decidir actuar" sobre la realidad interna y externa orientándose, construyendo proyectos y metas) y crear (construir cultura, construir algo desde algo, no desde la nada, simbolizando la notación de signos; darse cuenta de algo -notar- y darle significado -significar-, construyendo símbolos de nuestra cultura e interpretando la realidad por medio de los símbolos).

\subsection{Sistematización de rasgos de carácter que determinan el significado de 'educación'}

En mi opinión, es posible sistematizar la complejidad del objeto educación desde tres ejes que determinan rasgos de carácter de la educación:

- La condición fundamentante de los valores en la educación

- La doble condición de agente-autor y agente-actor de cada sujeto respecto de su educación

- $\quad$ La doble condición para la educación de ámbito de conocimiento y de acción.

Respecto de la primera condición, hemos de decir que la educación carece de toda justificación inteligible, cuando se rechaza el carácter fundamentante de los valores, pues, dado que no tenemos que ser todos lo mismo en la vida necesariamente, se infiere que cada uno sólo decidirá realizarse de un modo concreto, cuando le sea posible desvelar el valor de esa forma específica de llevarse a cabo, con su capacidad y con la ayuda de los demás. Pero, además, como el hombre no nace perfecto, ni alcanza la perfección que le es propia de modo espontáneo, se sigue que no entenderá correctamente el valor de tal forma concreta de realizarse, mientras que la educación no ponga los medios adecuados para que él pueda forjarse una capacidad de elección lúcida. Y esta relación entre educación y valores es la que hace de la educación en valores sea una necesidad inexorable. La educación es siempre educación en valores y elección de valores y cualquier tipo de influencia no es educación, aunque cualquier tipo de influencia pueda ser transformada en un proceso de influencia educativo. Tenemos que conocer, estimar, y elegir valores; la educación en sí misma es un valor, enseña valores y, cuando educamos, estamos eligiendo valores, porque nos marcamos fines y los fines son valores elegidos. A los valores les damos sentido de acción responsablemente desde la resolución de la relación medio-fin. La relación educativa, desde la condición fundamentante del valor, se hace de carácter axiológico y se entiende necesariamente como educación en valores para la construcción de procesos y de hábitos operativos de elección que se concretan en creación de sentido responsable de acción, desde la perspectiva de vincular medios y fines

La condición fundamentante del valor hace que el objeto de conocimiento 'educación' sea como es: valores elegidos. Desde la perspectiva del valor, la educación implica relación valorelección, porque construimos fines y eso significa que tenemos que desarrollar hábitos operativos que nos permiten relacionar las cosas que elegimos y ordenarlas como fines $y$ como medios. Hay que lograr en cada educando hábitos operativos, que se vinculan al sentido de la acción responsable. La responsabilidad y el sentido de acción son principios de la educación vinculados al carácter axiológico de la misma.

Por medio de la primera condición, la educación adquiere carácter axiológico. Carácter axiológico significa que la educación es siempre educación en valores y elección de valores y cualquier tipo 
de influencia no es educación, aunque cualquier tipo de influencia pueda ser transformada en un proceso de influencia educativo. En cada acción nos marcamos fines, que son valores elegidos y les damos sentido de acción responsablemente desde la resolución de la relación medio-fin. Los valores son elegibles, porque nos marcamos fines, que son valores elegidos. $\mathrm{Y}$ así, el carácter axiológico determina la educación como construcción de procesos, de relación medios-fines.

Respecto de la segunda condición, hemos de decir que el significado de agente marca un rasgo de carácter en la educación que no puede soslayarse, so pena de renunciar a educar. Se piensa siempre en la relación educativa como una relación entre dos, pero lo cierto es que la relación educativa es, de manera inequívoca, relación de uno consigo mismo. En la relación educativa somos cada uno de nosotros agentesactores que nos dejamos guiar y obedecemos a las personas que ejercen la condición de educadores. Realizamos un montón de operaciones guiados para educarnos. Pero, además, somos agentes-autores que nos guiamos a nosotros mismos en procesos de educación, decidiendo nuestras metas e integrando nuestros actos en nuestros proyectos. Por medio de la educación emprendemos la terea de ser actores y autores de nuestros proyectos, incluso si nuestra decisión es la de actuar según nos digan los demás. En cada caso, como agentes, estamos abocados por la educación a emprender la tarea de ser autores y actores de nuestros propios proyectos.

Desde la perspectiva de agentes, la peculiaridad de la acción educativa no estriba en el hecho de que sean uno o dos agentes, sino en la incuestionable verdad de que cada persona es agente -actor y autor- de su propio desarrollo de alguna manera y por consiguiente hay que lograr en cada educando hábitos volitivos, de querer las cosas y comprometerse con ellas, obligándose, y hábitos proyectivos, que le permiten integrar las cosas en sus proyectos, identificándose con ellos y estableciendo metas. Los hábitos volitivos se vinculan al compromiso personal y los hábitos proyectivos se vinculan al sentido de vida. Es decir, que yo educo para que el educando pueda educarse y decidir y desarrollar su proyecto de vida y formación. No sólo operamos (elegimos hacer cosas, hacemos operaciones, actuamos), también nos obligamos (compromiso voluntario) y proyectamos (hacemos proyectos, decidimos actuar). En la relación educativa, el educando es también sujeto de su educación que ha de encontrar el control de su propia vida, desarrollando el sentido patrimonial de su condición humana individual, social, histórica y de especie. Me marco fines, pero, además, me obligo a mí mismo y controlo con autonomía mi elección, decidiendo las acciones desde mi proyecto, incluso si mi proyecto decidido es hacer lo que me digan los demás. Desde el punto de vista de los agentes, la educación se hace de carácter personal y patrimonial y exige entender la relación valor-obligación y valor-decisión, porque en la acción educadora, junto al hábito operativo, tienen su lugar los hábitos volitivos y los hábitos proyectivos (Ferrater, 1979, pp. 119155; Dearden, Hirst, Peters, 1982).

Por medio de la segunda condición, la educación adquiere carácter personal y patrimonial. Carácter personal de la educación quiere decir que la acción educativa respeta la condición de agente del educando y lo prepara para comprometerse y obligarse personalmente (es el origen genuino de su elección), de manera voluntaria, en sus actuaciones y para inventar o crear modos originales-singulares (que nacen en él y de él) de realización de la existencia, afrontando su condición humana (individual, social, histórica y de especie), con autonomía y responsabilidad, dentro del espacio participado de una cultura, apartándose de la repetición o clonación de modelos preestablecidos (Arendt, 1974; Damasio, 2010; Gervilla, 2000, Haidt, 
2006; Marina, 2009; Morin, 2009; Pinker, 2011; Mosterín 2008).

Carácter personal de la educación significa que nos obligamos a actuar como procede, bajo las consideraciones del deber simple, el deber urgente y el deber fundamental, cualquiera que sea la forma de racionalidad que hayamos utilizado para comprender la situación. Además de hábitos operativos, necesitamos hábitos volitivos de compromiso y obligación personal a la acción. Esto marca el sentido personal de la educación como compromiso propio y original, es decir, nacido de uno mismo hacia su educación, que no debe ser vista alejada de la existencia del otro y de lo otro en cada intervención. Estamos obligados a ser actores y autores en la acción educativa respecto de uno mismo y del otro y de lo otro. Nos comprometemos con los valores voluntariamente para cumplir reglas y normas. El compromiso y el origen de la acción en la persona que es agente son principios de educación vinculados al carácter personal.

Carácter patrimonial, significa que, cuando nos marcamos fines, no sólo hacemos una estimación del valor, sino que también asumimos ese valor en la finalidad como una parte integrante de nuestro proyecto de vida; hacemos de nosotros mismos, nuestro propio patrimonio: nos identificamos en la decisión, nos individualizamos y determinamos nuestro sentido de vida. La identidad, la individualización y el sentido de vida son principios de la educación vinculados al carácter patrimonial. Afirmar el carácter patrimonial de la educación quiere decir que somos, cada uno de nosotros mismos, un patrimonio; que aprendemos a elegir, a comprometernos y a decidir nuestras metas, integradas en nuestro proyecto de vida, dando respuesta a nuestras necesidades en cada circunstancia: nos construimos a nosotros mismos como nuestro patrimonio más propio. Decidir cuál de nuestras necesidades debe ser atendida, aquí y ahora, en nuestro proyecto de vida, supone deliberar y asumir, atendiendo a los conocimientos, valores, sentimientos, actitudes e intereses que tenemos en ese momento; un patrimonio que nosotros podremos corregir $y$ variar, amparados en las oportunidades, en las circunstancias y en la educación recibida, pero que no podemos evitar tener en el momento de adoptar la decisión. El carácter patrimonial determina la educación como construcción de metas y proyectos personales. La finalidad se convierte en meta, porque se integra en nuestros proyectos.

Respecto de la tercera condición, se sigue que yo puedo elegir hacer algo, puedo comprometerme con ese algo e incluso puedo decidir integrar ese algo como parte de mis proyectos, pero, a continuación, tengo que realizarlo, debo pasar del pensamiento a la acción, debo pasar del valor realizado y realizable a la efectiva realización. Desde la tercera condición, hay que insistir en que la educación es un ámbito de realidad susceptible de conocimiento y una acción que se desempeña mediante la relación educativa. Cabría decir, por tanto, que a la educación le convienen tanto los métodos de pensamiento, como los métodos de acción, en el sentido más clásico y universal de métodos propios de la racionalidad teórica y de la racionalidad práctica (Mosterín, 2008b). Esta doble condición identifica la complejidad de la acción educativa para el conocimiento pedagógico, que debe resolver en cada caso la relación teoría-práctica: debo pasar del pensamiento y del conocimiento a la acción. Y para eso no basta con conocer, elegir, comprometerse y decidir; hay que dar un paso más y sentir, es decir, vincular afecto, valor y expectativas personales para que se produzca sentimiento en forma de vinculación positiva de apego hacia el valor de lo logrado o de lo que queremos lograr. La realización efectiva de la acción exige ejecutar por medio de la acción, lo comprendido e interpretado, expresándolo. 
Y para que esto sea posible, tenemos que hacer una integración afectiva, pues nos expresamos con los sentimientos que tenemos en cada situación concreta y vinculamos afectivamente (mediante apego positivo) lo que queremos lograr con valores específicos; pero, también, necesitamos hacer integración cognitiva relacionando ideas y creencias con nuestras expectativas y convicciones, para que podamos articular valores pensados y creídos con la realidad, porque nuestra acción se fundamenta desde la racionalidad, de manera explícita, con el conocimiento. $Y$ necesitamos, además, hacer una integración creativa, es decir, debemos dar significado a nuestros actos por medio de símbolos, porque cada acto que realizamos requiere una interpretación de la situación en su conjunto y en relación al conjunto de nuestras acciones y proyectos dentro de nuestro contexto cultural: construimos cultura simbolizando.

Necesitamos hábitos afectivos, pero la realización concreta de la acción no es posible sin el hábito intelectual y sin el hábito creativo, simbolizante-creador. El hábito operativo, el hábito volitivo y el hábito proyectivo exigen, para realizar la acción, el hábito afectivo que se deriva de la relación valor-sentimiento y genera experiencia sentida del valor. Nos desplazamos de la sensibilidad al sentimiento y vinculamos, con apego positivo, lo que queremos hacer con lo que es valioso, para resolver la situación con hábitos intelectuales y creativos.

Las cualidades personales de los agentes le imprimen carácter a la intervención, como concreta y singular puesta en escena, porque las personas no pueden dejar de tener los valores y los sentimientos que tienen en cada situación concreta. $Y$ ese sentido personal y singular nos pone en situación de entender que la acción educativa obliga a asumir la relación valor-sentimiento y nos ofrece, no sólo una perspectiva teórico-práctica, sino también una perspectiva artística y estética intrínseca.
Por medio del sentimiento manifestamos el estado de ánimo que se ha producido, según se cumplan o no nuestras expectativas en la acción; manifestamos y esperamos reconocimiento de nuestra elección; manifestamos y esperamos aceptación de nuestro compromiso voluntario; manifestamos y esperamos acogida nuestros proyectos y manifestamos entrega a ellos. Elegir, comprometerse decidir y sentir positivamente un valor tiene su manifestación afectiva en actitudes de reconocimiento, aceptación, acogida y entrega a la acción. Lo que caracteriza a la actitud es su condición de experiencia significativa de aprendizaje nacida de la evaluación afectiva de los resultados positivos o negativos de la realización de una determinada conducta.

Por medio de la tercera condición la educación adquiere carácter integral, gnoseológico y espiritual. Carácter integral quiere decir desarrollo dimensional integrado de cada educando desde su actividad común interna: pensar, sentir afectivamente, querer, elegirhacer (operar), decidir-actuar (proyectar) y crear (construir simbolizando), para desarrollar con posibilidades de éxito la condición humana individual, social, histórica y de especie en las situaciones que se nos plantean en todos los ámbitos de la vida (personal, familiar, local, escolar, profesional, etcétera). Carácter integral de la educación quiere decir educación de todo el educando, como un todo desde su actividad interna, no como una suma de partes. Positividad y desarrollo dimensional son principios de educación derivados del carácter integral de la misma, porque la afectividad educada reclama positividad y desarrollo dimensional, como principios.

Desde la perspectiva del carácter integral de la educación, puede decirse que toda educación es intelectual, pero no todo en la educación es educación de la inteligencia; hay otras dimensiones de intervención educables, que 
pueden ser atendidas específicamente. Y lo mismo se puede decir de cada una de las otras dimensiones de intervención: toda educación es afectiva, pero no todo en la educación es educación de la afectividad; toda educación es volitiva, pero no todo en la educación es educación de la voluntad; toda educación es operativa, pero no todo en la educación es educación de la capacidad de obrar-hacer; toda educación es proyectiva, pero no todo en la educación es educación de la capacidad de decidir moralmente; toda educación es creadora y concienciadora, pero no todo en la educación es educación de la espiritualidad, de la aprehensión significativa, de la creatividad.

Desde el punto de vista pedagógico, en la acción educativa integral se unen inteligencia (cognición y razonamiento), afectividad $y$ emociones (sentimiento dimensionado), volición (querer con determinación y compromiso), operación y proyección (sentido de acción y sentido de vida, construcción de procesos y construcción de metas), creación (construcción de cultura simbolizada) de las personas en desarrollo y variables contextuales que nos permiten configurar un "todo concordado" entre valores, pensamientos, sentimientos, obligaciones, elecciones, decisiones y creaciones. Todas las dimensiones intervienen en cada caso y la educación no se resuelve atendiendo a una de ellas solamente.

Carácter gnoseológico quiere decir que somos capaces de integración cognitiva, o sea, que aprendemos a relacionar ideas y creencias utilizando las formas de pensar, de manera que podamos articular valores pensados $y$ valores creídos con la realidad por medio del conocimiento y la racionalidad en cada uno de nuestras elecciones, voliciones, proyectos, sentimientos, pensamientos e interpretaciones creativas. La integración cognitiva es principio de educación derivado del carácter gnoseológico.
Carácter espiritual significa que generamos consciencia y creatividad que hace posible, desde la propia condición humana, crear símbolos para notar y significar el yo, el otro y lo otro, en el mundo físico, en el mundo de los estados mentales y en el mundo de los contenidos de pensamiento y sus productos. Carácter espiritual de la educación significa que la educación se hace al modo humano y genera eventos mentales en los educandos; mejoramos la toma de conciencia de nosotros mismos y de la realidad por medio de símbolos, al modo humano, es decir, como corporeidad mental que integra de manera emergente en el cerebro lo físico y lo mental y establece una forma de relación creadora entre el yo, el otro y lo otro, por medio de símbolos. Carácter espiritual quiere decir que podemos construir cultura, es decir, que podemos construir simbolizando. $\mathrm{La}$ integración simbolizante-creadora es principio de educación vinculado al carácter espiritual.

Para mí, la educación se define atendiendo a rasgos de carácter que determinan el significado de educación. Nada es educación, si no cumple las condiciones de uso común, finalidad y los rasgos de carácter. Toda acción educativa se distingue de las demás por el uso común y por la actividad, pero además se singulariza, atendiendo a criterios de definición real porque, desde la complejidad objetual de educación, a la acción educativa se le atribuyen rasgos de carácter que determinan el significado. $Y$ así, puede decirse que toda acción educativa tiene carácter axiológico, personal, patrimonial, integral, gnoseológico y espiritual, tal como se resume en el Cuadro 2. 


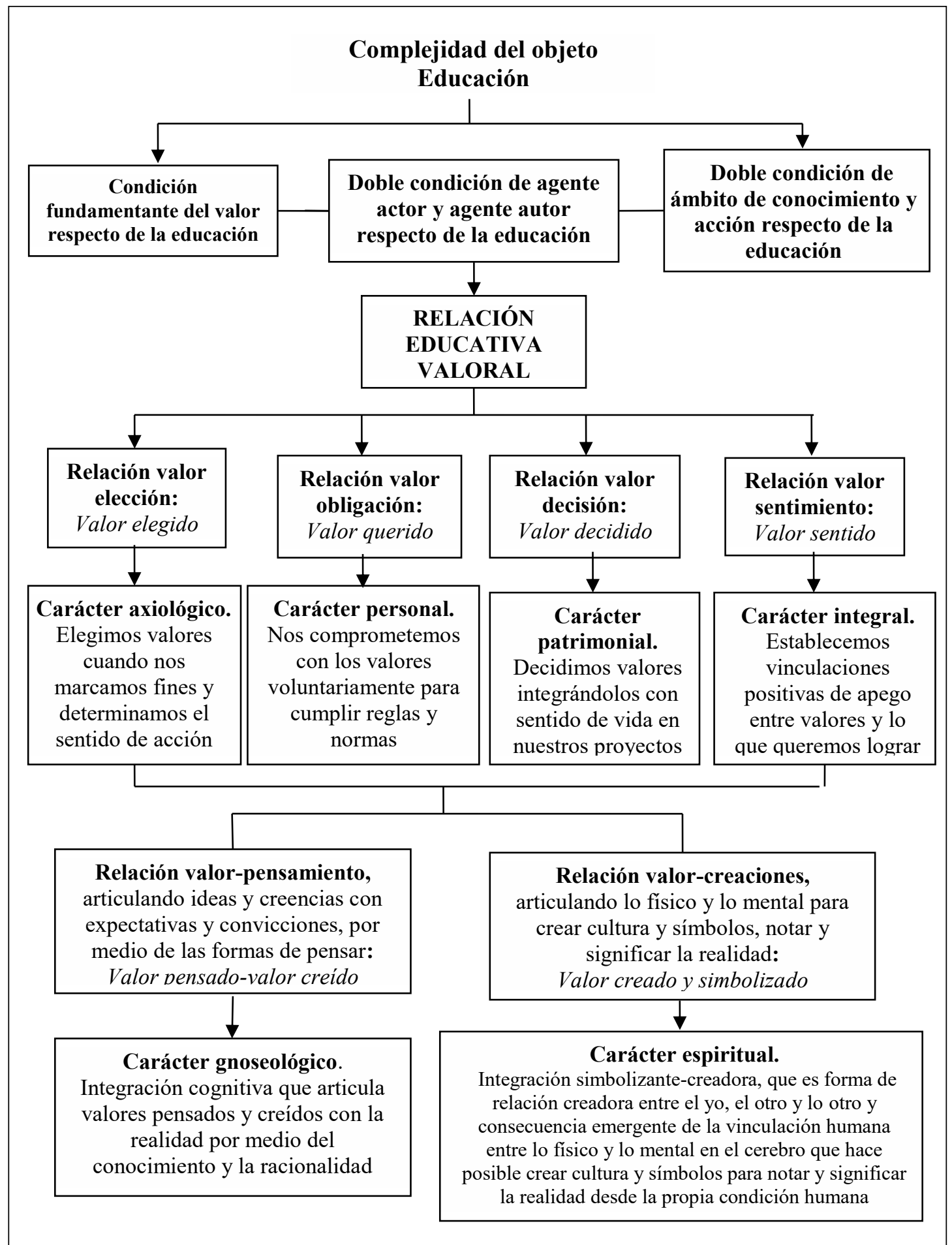

Fuente: Touriñán, 2014a, p. 645.

4.3. La relación educativa requiere concordancia entre valores y sentimientos en el paso del conocimiento a la acción
Yo puedo elegir hacer algo, puedo comprometerme con ese algo y puedo decidir integrar ese algo como parte de mis proyectos, pero, a continuación, tengo que realizarlo, debo 
pasar del pensamiento a la acción, debo pasar del valor realizado y realizable a la efectiva realización. Y esto implica en cada ejecución de la acción, interpretación, comprensión y expresión. No hay educación sin afectividad, es decir, sin afrontar el problema de generar experiencia sentida del valor. Y para ello necesitamos hábitos operativos, volitivos, proyectivos, afectivos, cognitivos y creativos. La efectiva realización de la acción requiere hábitos operativos, volitivos y proyectivos, pero, además, necesitamos hábitos afectivos, cognitivos y creativos. $Y$ solo de ese modo llegamos a la realización de la acción que siempre implica ejecutar la acción, atendiendo a la comprensión interpretación, y expresión (integración cognitiva, simbolizante-creadora y afectiva).

Por medio del sentimiento manifestamos el estado de ánimo que se ha producido por cumplir o no nuestras expectativas en la acción; manifestamos y esperamos reconocimiento de nuestra elección; manifestamos y esperamos aceptación de nuestro compromiso voluntario; manifestamos y esperamos acogida nuestros proyectos y manifestamos entrega a ellos. Elegir, comprometerse, decidir y realizar un valor, tiene su manifestación afectiva de vinculación y apego, en actitudes de reconocimiento, aceptación, acogida y entrega a la acción. Lo que caracteriza a la actitud es su condición de experiencia significativa de aprendizaje nacida de la evaluación afectiva de los resultados positivos o negativos de la realización de una determinada conducta, tal como reflejamos en el Cuadro 3, bajo la forma de relación compleja valor-actividad común interna del educando, concordando valores y sentimientos en el paso del conocimiento a la acción:

Cuadro 3: Concordancia valor-sentimiento en el paso del conocimiento a la acción

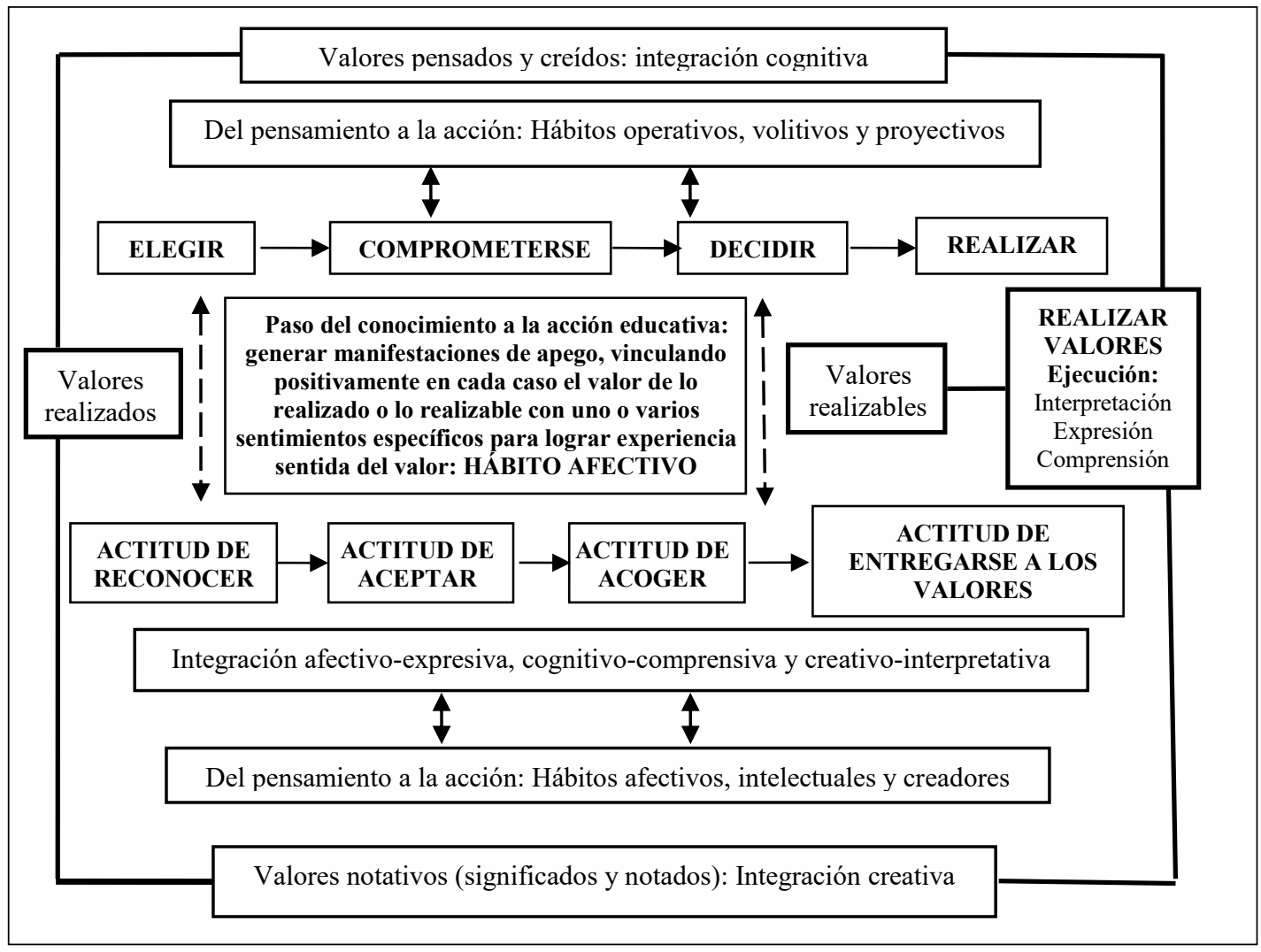

Fuente: Touriñán, 2014a, p. 356. 
Llegamos a la realización concreta de un valor, contando con las oportunidades, pero siempre hemos de disponer de hábitos operativos, volitivos, proyectivos, afectivos, intelectuales y hábitos, notativos-significantes, creadores. Cada vez que realizamos algo pensamos, sentimos, queremos, elegimos hacer, decidimos proyectos y creamos con símbolos. $Y$ solo de ese modo llegamos a la realización concreta de algo que siempre implica, elegir procesos, obligarse (comprometerse voluntariamente), decidir metas y proyectos (de acuerdo con las oportunidades y en cada circunstancia), sentir (integrar afectivamente, expresando), pensar (integrar cognitivamente, comprendiendo) y crear cultura (integrar creativamente, interpretando, dando significado mediante símbolos).

Solo por este camino se llega a la realización de una acción como agente autor, de acuerdo con las oportunidades y en cada circunstancia. La realización efectiva de la acción exige, en la ejecución de la acción, interpretación, comprensión y expresión. La realización exige ejecutar mediante la acción lo comprendido e interpretado, expresándolo. Y para que esto sea posible, además de hacer una integración afectiva (expresión), pues nos expresamos con los sentimientos que tenemos en cada situación concreta y vinculamos afectivamente, mediante apego positivo, loquequeremoslograrconvalores específicos, necesitamos hacer integración cognitiva (comprensión de lo pensado y creído), relacionando ideas y creencias con nuestras expectativas y convicciones, para que podamos articular valores pensados y creídos con la realidad, porque nuestra acción se fundamenta de manera explícita desde la racionalidad con el conocimiento. Pero necesitamos, además, hacer una integración creativa (interpretación simbolizante-creadora), es decir, debemos dar significado a nuestros actos por medio de símbolos, que interpreten cada acto, porque cada acto que realizamos requiere una interpretación de la situación en su conjunto y en el conjunto de nuestras acciones y proyectos dentro de nuestro contexto cultural. La integración creativa articula valores y creaciones, vinculando lo físico y lo mental para construir cultura, simbolizando (Touriñán, 2019b).

Si nuestros razonamientos son correctos, la doble condición de conocimiento y acción nos coloca en la visión integral de la complejidad de la acción. El hábito operativo, el hábito volitivo y el hábito proyectivo exigen, para realizar la acción, el hábito afectivo que se deriva de la relación valor-sentimiento en cada acción realizada y permite obtener, en la realización, la experiencia sentida del valor. La realización del valor no es posible en su concreta ejecución, si no hacemos, de acuerdo con las oportunidades y en cada circunstancia, una integración afectiva, cognitiva y creadora en cada acción.

Desde la perspectiva del paso del conocimiento a la acción, en cada actuación hacemos un camino de doble dirección que nos permite ir:

- De la elección, la obligación y la decisión a la afectividad y viceversa

- De la afectividad a la cognición y a la creatividad y viceversa

- De la cognición y la afectividad y la creatividad a la estética y viceversa.

La creatividad y la afectividad se vinculan por medio de las actitudes hacia la innovación y las experiencias sentidas de la emoción y del valor; la creatividad nos produce sentimientos singulares y los sentimientos impulsan o inhiben la creatividad. La cognición y la creatividad se vinculan por la posibilidad de generar una integración cognitiva superior en cada aprehensión y comprensión de la realidad innovada; usamos la cognición y la creatividad para comprender e interpretar, significar e innovar (Novak, 1998). La cognición y la afectividad se vinculan porque somos afectividades conscientes y pensantes: relacionamos ideas 
y creencias y generamos convicciones sobre lo que elegimos, lo que nos compromete y lo que decidimos, porque lo sentimos, alcanzando experiencia sentida de lo valioso, de la realidad, de nuestros actos y de nuestros pensamientos. La cognición, la creatividad y la afectividad se vinculan a la estética, porque, además de comprender, somos capaces de hacer interpretaciones simbólicas y atribuir significado a la belleza como armonía o relación entre las formas, generando experiencia sentida de esa relación. En la articulación de la acción somos capaces de pasar, en cada acto, de la sensibilidad al sentimiento y de la cognición y la afectividad a la creatividad y a la estética.

Cada caso de intervención es un ejercicio de libertad, compromiso, decisión, pasión y compasión; cada caso de acción pedagógica exige resolver la concordancia de valores y sentimientos en cada situación como manifestación explícita de actitudes de reconocimiento, aceptación, acogida y entrega a la acción educativa. Y, aun así, con esto no se resuelve en su totalidad el paso del conocimiento a la acción porque requiere, además, razón y creación: cada caso de intervención es una puesta en escena cuya realización implica, de acuerdo con las oportunidades y en cada circunstancia, ejecución, interpretación, comprensión y expresión, que exigen además de la integración afectiva, la integración cognitiva y la integración simbolizante-creadora.

Cada actuación es un camino que implica el valor pensado y creído, valor creado, simbolizado y significado, valor elegido, valor comprometido, valor decidido y valor sentido. El paso del conocimiento a la acción nos instala en la complejidad del valor realizado, del valor realizable y de la realización del valor. La relación educativa se hace de carácter axiológico, personal y patrimonial y de carácter integral, gnoseológico y espiritual.
Dentro del marco que acabo de exponer, yo quiero hablar en este artículo de la relación educativa como acto concreto. No como una cuestión de educabilidad que nos llevaría a enumerar las capacidades humanas que hacen posible recibir educación. Tampoco como una cuestión de educatividad, que nos llevaría a enumerar las competencias que hacen viable que un sujeto pueda dar educación. Por supuesto, tampoco como una cuestión de libertades formales y reales que garantizan la oportunidad de educar en un territorio legalmente determinado que constituye la forma institucional de plantear la relación entre justicia y cuidado. Yo quiero deliberar sobre el propio concepto "relación educativa" que aúna en un solo acto educabilidad, educatividad y oportunidad de educar y quiero deliberar sobre ese concepto, cultivando una reflexión independiente, como diría Herbart. El resultado de mi pensamiento sobre esa cuestión es lo que pretendo ofrecer. Mi planteamiento es el siguiente (Touriñán, 2016 y 2017a):

- La relación educativa es la forma sustantiva de la intervención educativa, es su acto concreto. La relación educativa se identifica con la interacción que establecemos para realizar la actividad de educar $\mathrm{y}$, precisamente por eso, la relación educativa puede ser vista como el conjunto de cuidados que hacemos para educar. Es interacción de identidades para educar.

- En la relación educativa reforzamos la capacidad de hacer compatible la acción de educar y nuestro conocimiento de tal actividad, con objeto de responder en cada acción educativa concreta a la pregunta qué actividades cuentan para educar y qué cuenta en las actividades educativas. Para ello hay que elegir y valorar en relación con el conocimiento que tenemos de la acción educativa, ya que 'educación' tiene significado propio. 
Por consiguiente, veo la relación educativa, ni más, ni menos, como el ejercicio de la educación y ello implica asumir la complejidad propia de la educación y que he sistematizado en un triple eje condicional: valores, agente actor y autor y la concurrencia de conocimiento y acción. Esta triple condición debe cumplirse en cada caso concreto de la relación educativa, porque desde la complejidad se fijan los rasgos que determinan realmente el significado de 'educativo' y permiten singularizar la relación respecto de otros tipos de relaciones. Si no se cumplen esos rasgos de significado que caracterizan a 'educación', la relación educativa será genéricamente relación, pero no podrá ser específicamente educativa, porque no lograría caracterizarse frente a otras relaciones. Debemos asumir que:

- $\quad$ en la relación educativa se crea una vinculación entre valor y elección, de manera que podemos mejorar el sentido responsable de acción, en cumplimiento del carácter axiológico de la educación, construyendo procesos desde la relación medios-fines

- $\quad$ en la relación educativa se crea una vinculación entre valor y obligación, de manera que podemos mejorar el compromiso voluntario de acción, en cumplimiento del carácter personal de la educación

- en la relación educativa se crea una vinculación entre valor y decisión, de manera que podemos mejorar el sentido de vida individualizado que tiene esa acción, en cumplimiento del carácter patrimonial de la educación, construyendo metas

- $\quad$ en la relación educativa se crea una vinculación de apego o dependencia entre valor y sentimiento de manera que podemos orientarnos hacia el logro de experiencia sentida del valor por medio de la integración afectiva, en cumplimiento del carácter integral de la educación.
- $\quad$ en la relación educativa se crea una vinculación entre ideas y creencias con las expectativas y convicciones, por medio de las formas de pensamiento, de manera que somos capaces de integrar cognitivamente los valores pensados y creídos con la realidad, en cumplimiento del carácter gnoseológico de la educación

- $\quad$ en la relación educativa se crea una vinculación entre signos y significados, debido a la relación humana de lo físico y lo mental, de manera que somos capaces de hacer integración simbolizante-creadora del valor en cumplimiento del carácter espiritual de la educación y darle significado a la condición humana en el mundo simbolizado, construyendo cultura

- $\quad y$, por último, como voy a exponer en el epígrafe siguiente, en la relación educativa se crea una vinculación entre categorías de espacio-tiempo-género-diferencia específica, respecto de la relación entre el yo, el otro y lo otro en cada acto educativo, de manera que somos capaces de mantener en cada intervención el sentido territorial, duradero, cultural y formativo de la educación.

Cada una de estas vinculaciones son exigencias, por principio de significado, de educar: nada es educativo si no tiene los rasgos propios de carácter y sentido que son inherentes al significado de educación; sólo así la relación será educativa. La relación educativa es, por tanto, interacción para educar y ello implica asumir la complejidad propia de la educación, y las exigencias derivadas de los rasgos propios del significado de educar, que han de manifestarse, en cada intervención por medio de la actividad común (Touriñán, 2016).

Intervenimos para establecer una relación educativa que logre educar y para ello utilizamos la actividad del educando y del educador. La relación educativa es el foco de la función de educar en la que se produce la interacción entre 
yo, el otro y lo otro. $Y$ precisamente por eso, desde la perspectiva de la relación educativa, la interacción de identidades (la relación con el otro) es un componente definitorio en la educación. Respecto de nosotros mismos y de los demás, en los procesos de auto y heteroeducación, tenemos que lograr en la relación educativa el paso del conocimiento a la acción y ello exige lograr una puesta en escena en la que la concordancia valores-sentimientos se produzca: elegir, comprometerse, decidir y realizar tienen que tener su concordancia en la acción concreta en actitudes de reconocimiento, aceptación, acogida y entrega a la tarea y al logro, respectivamente.

En la relación educativa, por tanto, buscamos la concordancia valores-sentimientos en cada interacción y para ello elegimos, nos comprometemos, decidimos y realizamos lo decidido. $Y$ para realizar, ejecutamos mediante la acción lo comprendido e interpretado, expresándolo. La realización exige ejecutar mediante la acción. Y esa acción, además de la actividad común interna del sujeto, utiliza siempre la actividad común externa del educando. Realizamos por medio del juego, del trabajo, del estudio, de la indagación-exploración, de la intervención en cada acto y de la relación que se establezca entre el yo y las cosas usadas en cada interacción, que está definida siempre como relación yo-el otro-lo otro. $Y$ todo esto es visto por el educador en la relación educativa. Veamos el sentido pedagógico de la educación a continuación con más detalle.

\section{EL SENTIDO PEDAGÓGICO DE LA EDUCACIÓN COMO VINCULACIÓN ENTRE EL YO, EL OTRO Y LO OTRO EN CADA ACTO EDUCATIVO, ATENDIENDO A CATEGORÍAS QUE CUALIFICAN SU SIGNIFICADO}

En la relación educativa actuamos siempre con una específica perspectiva de enfoque o cualificación, que se infiere de la vinculación que se establece entre el yo y el otro, en cada acto educativo, atendiendo a las categorías conceptuales clasificatorias de espacio, tiempo, género y diferencia específica; es decir, apelamos, con propiedad, al sentido de la educación. El sentido de la educación es lo que la cualifica. Los agentes actúan y sus acciones tienen sentido de acción (relación fines-medios) y sentido de vida (relación decisión-proyectosmetas), pero, además, tienen el sentido propio del significado de la acción que realizamos: a la acción educativa le corresponde un sentido que es inherente al significado de 'educación' (Touriñán, 2013a). El significado de la educación está conformado por los rasgos de carácter y de sentido. El carácter determina el significado de 'educación', el sentido, derivado de las vinculaciones de agentes en cada acto educativo, cualifica el significado de 'educación'.

El carácter de la educación nace de la complejidad objetual de educación. Como acabamos de ver en el epígrafe anterior, es posible sistematizar la complejidad del objeto educación desde tres ejes que determinan rasgos de carácter de la educación: la condición fundamentante de los valores en la educación, la doble condición de agente-autor y agenteactor de cada sujeto respecto de su educación y la doble condición para la educación de ámbito de conocimiento y de acción. En nuestros días, el carácter de la educación se establece como carácter axiológico, personal, patrimonial, integral, gnoseológico y espiritual (Touriñán, 2014c).

El sentido pedagógico de la educación nace de la vinculación que se establece entre el yo, el otro y lo otro en cada acto educativo. En cada situación concreta nos percatamos y somos conscientes de las cosas y de nosotros y generamos símbolos que atribuyen significado al yo, al otro y a lo otro y permiten interpretar, transformar y comprender la realidad y crear nuevas formas y cultura. Por esta posibilidad 
de crear símbolos para notar y significar cultura y realidad desde su propia condición humana, podemos hablar de la condición humana individual, social, histórica y de especie, porque el hombre se adapta, acomoda y asimila su condición desde un mundo simbolizado. Nuestros hábitos creadores y simbolizantes nos permiten interpretar la relación entre el yo, el otro y lo otro en cada caso (Touriñán, 2014a; Touriñán, Dir, 2012).

La vinculación entre el yo, el otro y lo otro es un tipo de vinculación que requiere conjugar en el desarrollo formativo de la condición humana la identidad, lo territorial y el horizonte interrogativo de la realidad y de la existencia, articulando en cada acción los límites de lo singularmente personal, lo próximo ambiental y lo universal, tres categorías vinculadas al "yo", "el otro", y "lo otro" en cada caso concreto de actuación (Touriñán, 2015). El sentido pedagógico de la educación se establece en nuestros días, desde las vinculaciones entre el yo, el otro y lo otro en cada acto educativo, atendiendo a las categorías conceptuales de espacio, tiempo, género y diferencia específica, como un sentido espacial (territorializado), temporal (durable), de género (cultural) y de diferencia especifica (formativo). Desde el punto de vista del sentido de la educación, toda acción educativa se cualifica como de sentido territorial, durable, cultural y formativo y admite variadas respuestas, atendiendo a las circunstancias de cada caso (Touriñán, 2016).

En Pedagogía, el sentido de la educación es un elemento fundamental en el significado de educación, no porque se cualifique la vinculación del yo, el otro y lo otro en cada acción, atendiendo a las categorías conceptuales de espacio, tiempo, género y diferencia específica, sino porque, si no se conjuga en cada acción la identidad, lo territorial y el horizonte interrogativo de la realidad y de la existencia, no abarcaremos la condición de agente de la educación en su extensión: pues mi derecho 'a' y 'de' la educación es un derecho legal y legítimamente encuadrado en un marco legal territorial y con unas circunstancias concretas que condicionan oportunidades específicas. Si no se salvan los límites de lo singularmente personal, lo próximoambiental y lo universal, el agente pierde su ubicación de sujeto situado en el mundo. Sin esa reserva, no distinguiremos entre la integración territorial de las diferencias culturales y la inclusión transnacional de la diversidad cultural en cada agente de la educación.

\subsection{El sentido pedagógico de la} educación se infiere de la vinculación entre el yo, el otro y lo otro en cada acto educativo y cualifica el significado del término, atendiendo a las categorías conceptuales clasificatorias de espacio, tiempo, género y diferencia específica

En el debate pedagógico hablamos de educación intelectual, afectiva, volitiva, operativa-intencional, proyectiva-moral y creativa. Hablamos también de educación rítmica, verbal, lingüística, matemática $\mathrm{y}$ audiovisual-virtual. Hablamos, además, de educación religiosa, ambiental, científico-natural y sociohistórica. Cada uno de estos tres modos de hablar, refleja en particular un modo distinto de abordar la educación: en el primer caso, hablamos de la pedagogía de las dimensiones generales de intervención; en el segundo caso, hablamos de la pedagogía de las formas de expresión; en el tercer caso, hablamos de la pedagogía de las áreas de experiencia. Las áreas de expresión y experiencia constituyen ámbitos de educación y son susceptibles de intervención pedagógica. Cada uno de estos ámbitos puede ser desarrollado atendiendo a las dimensiones generales de intervención, desde una determinada perspectiva de orientación o finalidad cualificadora. La educación puede tener sentidos filosóficos diversos: puede ser 
humanista, localista, globalista, nacionalista, comunitarista, asimilacionista, multiculturalista, interculturalista, intelectualista, relativista, laicista, etcétera (Carr, 2014). Pero, cuando hablamos del sentido como característica del significado de educación, queremos referirnos a una cualificación propia del significado de educación, vinculada a la relación entre el yo, el otro y lo otro en cada acto educativo, atendiendo a las categorías clasificatorias de espacio, tiempo, género y diferencia específica. Desde esta perspectiva, cualquier acción educativa, sea humanista, socialista, etc., tendrá sentido territorial, duradero, cultural y formativo; tendrá el sentido inherente al significado de educación. Tendrá sentido pedagógico

Cuando hablamos de sentido cultural, por ejemplo, no estamos hablando de una dimensión general de intervención, ni de uno de los ámbitos de la educación (resultado de valorar el área de experiencia cultural como educación), ni de uno de los sentidos filosóficos atribuibles a la educación desde la perspectiva de las finalidades. Cuando hablamos de sentido cultural, estamos pensando en el sentido pedagógico: un rasgo cualificador, que es propio del significado de educación y que se integra en la orientación formativa temporal para la condición humana individual, social, histórica y de especie. Toda educación tiene, por principio de significado, sentido cultural, territorial, duradero y formativo.

En las sociedades abiertas, pluralistas y constitucionalmente aconfesionales, se evidencia la necesidad de modelos de intervención que propicien el sentido cultural como rasgo definitorio propio del significado de la educación, que admite diversas respuestas, desde el multiculturalismo al interculturalismo, desde el tratamiento simétrico al tratamiento asimétrico de las diferencias, desde la integración territorial de las diferencias a la inclusión transnacional de la diversidad, pero siempre desde una visión coherente con los rasgos de carácter y sentido inherentes al significado de educación. El sentido cultural de la educación se vincula al principio educativo de la diversidad y la diferencia, en tanto que rasgo definitorio que cualifica el significado de educación, atendiendo a la categoría conceptual y clasificatoria de 'género'.

El sentido pedagógico de la educación está vinculado a la respuesta formativa que en cada momento cultural se da a la condición humana individual, social, histórica y de especie. El sentido de la educación se integra en la orientación formativa temporal de la condición humana por medio de las materias escolares, pero no se confunde con las materias escolares de estudio, derivadas de las áreas culturales que están vigentes y consolidadas en cada momento sociohistórico. Esto es así y, precisamente por eso, tiene sentido decir que toda educación tiene que ser personal (que es rasgo determinante del significado y derivado de la complejidad objetual de 'educación'), pero no necesariamente toda educación es de matemáticas o de física o de literatura o de artes. Al mismo tiempo, tiene sentido decir que toda educación matemática, física, artística o literaria, etcétera, atendiendo a la vinculación que se establece entre el yo, el otro y lo otro en cada acto educativo, debe pensarse como educación con sentido territorial, durable, cultural y formativo. Este sentido pedagógico admite diversas respuestas concretas, según se trate de una materia escolar general o profesional, de formación ocasional, permanente o continua, de formación presencial o virtual, de formación sincrónica o asincrónica, etcétera.

El sentido pedagógico de la educación nace de la vinculación que se establece entre el yo, el otro y lo otro en cada acto educativo, atendiendo a las categorías conceptuales de espacio, tiempo, género y diferencia específica que están presentes en el significado de educación; es un 
tipo de vinculación que requiere conjugar en el desarrollo formativo de la condición humana la identidad, lo territorial y el horizonte interrogativo de la realidad y de la existencia, articulando en cada acción los límites de lo singularmente personal, lo próximo ambiental y lo universal, tres categorías vinculadas al "yo", "el otro", y "lo otro" en cada caso concreto de actuación (Touriñán, 2015 y 2013b).

Desde el conocimiento de la educación, el carácter y el sentido de la educación son los dos elementos que integran el significado de 'educación'; el carácter determina el significado; el sentido lo cualifica. Desde esta perspectiva, la educación se configura como una tarea $y$ un rendimiento orientado a desarrollar experiencia valiosa y conseguir el uso de las formas de expresión más adecuadas para ella, con objeto de imprimir en la educación, en cada intervención pedagógica, el carácter que determina el significado de educación desde su complejidad objetual (axiológico, integral, personal, patrimonial, gnoseológico y espiritual) y el sentido que cualifica el significado de la educación, desde la vinculación que se establece entre el yo, el otro y lo otro en cada acto educativo, atendiendo a las categorías conceptuales de espacio, tiempo, género y diferencia específica (territorial, durable, cultural y formativa). Al yo, en tanto que singularidad individualizada, hay que formarlo en todos los rasgos de carácter inherentes al significado de la educación. Al yo, en relación con el otro y lo otro, hay que formarlo en los rasgos de sentido inherentes al significado de educación y darle la respuesta adecuada de acuerdo con las oportunidades concretas y las circunstancias específicas de cada acción (Touriñán, 2014a).

En cada acto educativo se establece vinculación entre el yo, el otro y lo otro y se genera en la educación el sentido de cualificación espacial, temporal, de género y de diferencia específica. En cada acto educativo se concreta un sentido territorial, temporal, cultural y formativo, sin los cuales la educación no queda definida. Toda educación tiene sentido espacial (territorial), temporal (durable), de género (cultural) y de diferencia específica (formativa), cualquiera que sea el área de experiencia cultural con la que educamos y cualquiera que sea el sentido filosófico que le atribuye una sociedad a la educación (Touriñán, 2014b y 2015).

El sentido durable, territorial, cultural y formativo cualifica la acción educativa en cada caso concreto según las oportunidades. El sentido no determina sin más el significado de la educación. Atendiendo a estas cuatro categorías conceptuales clasificatorias, la vinculación entre el yo, el otro y lo otro en cada caso concreto nos permite hablar de educación permanente y ocasional, de educación presencial y no presencial, de educación sincrónica y asincrónica, de educación virtual, de educación local, global y glocal, de educación multicultural e intercultural, de educación vocacional, general y profesional, etc.

En cada acto educativo conjugamos la identidad, lo territorial y el horizonte interrogativo de la realidad y de la existencia, para salvar los límites de lo singularmente personal, lo próximoambiental y lo universal, tal como se resume en el Cuadro 4. 
Cuadro 4: Sentido pedagógico de la educación derivado de la vinculación establecida entre el yo, el otro y lo otro en cada acto educativo y que cualifica el significado desde las categorías conceptuales de espacio, tiempo, género y diferencia específica

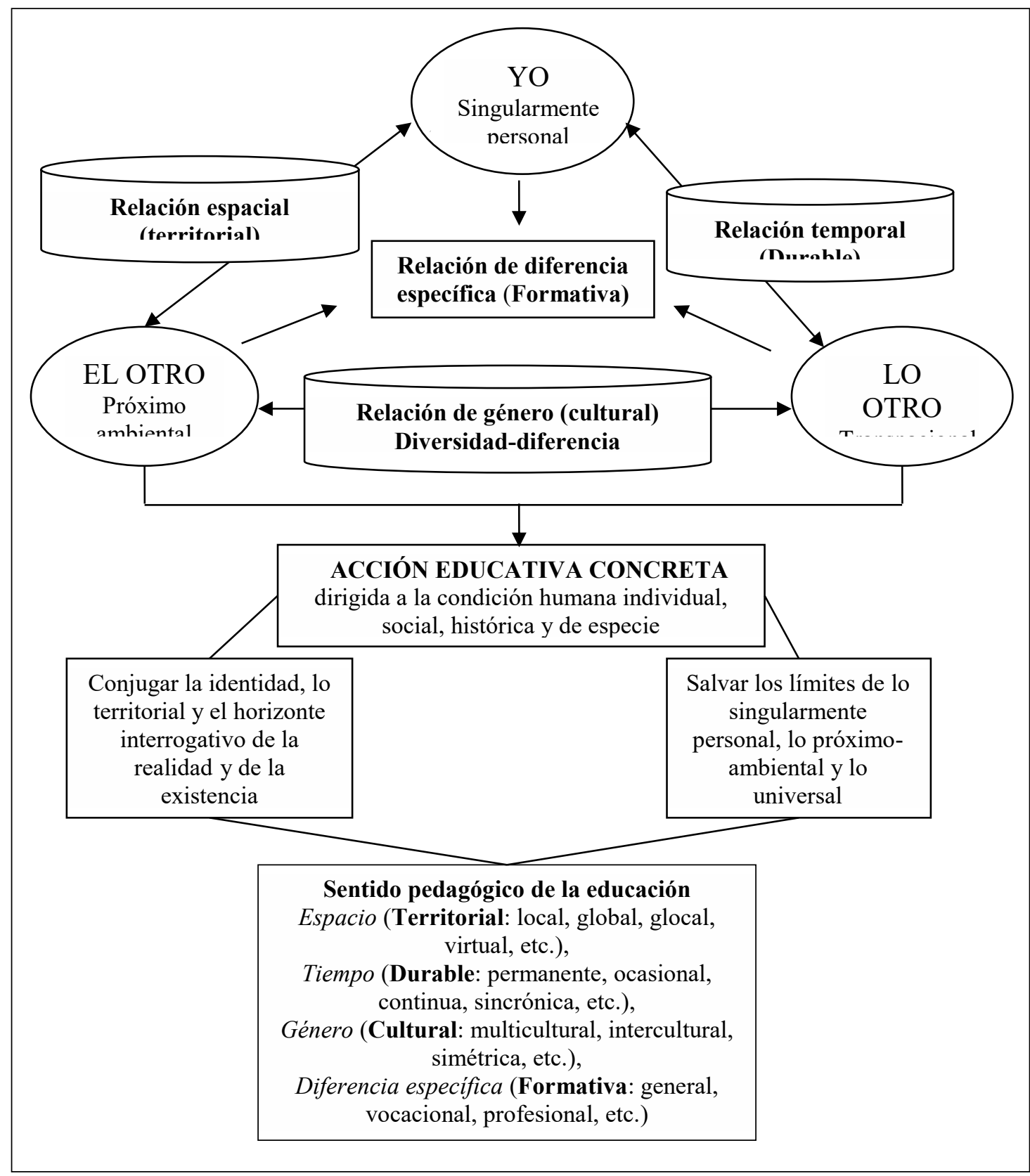

Fuente: Touriñán, 2014a, p. 500.

En cada acto educativo se establece vinculación entre el yo, el otro y lo otro de manera que, atendiendo a las categorías conceptuales clasificatorias de espacio, tiempo, género y diferencia específica, se genera en la educación el sentido territorial, durable, cultural y formativo.
En cada acto educativo, desde las relaciones entre el yo, el otro y lo otro, en sí mismas, se conjuga la identidad, lo territorial y el horizonte interrogativo de la realidad y de la existencia y en cada acción, desde las relaciones en sí mismas, se salvan los límites de lo singularmente 
personal, lo próximo-ambiental y lo universal. En cada acto educativo se concreta un sentido territorial, duradero, cultural y formativo sin los cuales la educación no queda definida. Toda educación tiene sentido temporal, territorial, cultural $y$ es específicamente formativa. El sentido de diversidad cultural, permanente o no, glocal o no y de formación vocacional o no, cualifica la educación en un concreto marco cultural y territorial. El sentido no determina sin más el significado de la educación; lo cualifica y esa cualificación tiene condicionamiento territorial integrado en cada orientación formativa temporal. Ni todo en la educación de la diversidad es fusión o integración cultural, por ejemplo, ni toda educación es educación, si propicia la fusión o la integración, porque no solo se respeta la diversidad desde la fusión o la integración. Es decir, siempre habrá una respuesta que marca el sentido de la educación respecto de la categoría conceptual "género", porque toda educación tiene sentido cultural, pero la respuesta educativa al sentido cultural de la diversidad no es sólo una, porque son igualmente reales y posibles las respuestas de tratamiento simétrico y asimétrico de las diferencias. $Y$ este modo de razonar se aplica a cada concreción de sentido: ni hay una sola respuesta de sentido educativo frente a la diversidad cultural, ni hay un solo tipo de respuesta educativa al sentido educativo derivado de la categoría conceptual espacio; ahora bien, la respuesta, por ser global, local o glocal, según los casos, tiene sentido territorial. Y así, sucesivamente:

- $\quad$ Entre el yo y el otro y lo otro siempre se da una relación de convivencia como interacción de identidades en un marco territorial. El principio básico de la convivencia es la socialización territorializada y precisamente por eso la socialización territorializada es principio de educación vinculado al sentido de esta. Desde la categoría conceptual "espacio", el sentido de la educación es, en nuestros días, territorial. Pero en sentido territorial, la educación no tiene que ser, ni de corte localista, ni de corte globalista, también puede ser glocal; puedo ir en determinados casos de lo local a lo global y viceversa de lo global a lo local. No hay una única respuesta, no se trata sólo de pensar localmente para actuar globalmente y hacer a todos a la imagen de "mi localidad nacional", ni se trata sólo de pensar globalmente para actuar localmente y hacer todos a la imagen de un mundo uniforme sin raíces identitarias culturalmente diversas. Atendiendo a la categoría conceptual de espacio, desde la perspectiva de la relación del yo y el otro, el sentido de la educación es territorial y no tiene que pensarse en una sola dirección. En la educación se da un sentido de cualificación espacial (sentido territorial: a veces glocal, a veces local, a veces global, a veces planetario, virtual, presencial, etcétera).

- $\quad$ Entre el yo y lo otro y el otro siempre se da una relación temporal, porque la realidad es inagotable y tenemos que interpretarla en cada acción. El tiempo, igual que el espacio, se vincula a la acción educativa bajo forma de durabilidad o duración, porque la actividad de educación, ya sea reglada o actividad en torno al tiempo libre, va más allá del tiempo escolar y de los procesos formales de intervención escolar; el perfeccionamiento progresivo es posible a lo largo de la vida de las personas y precisamente por eso perfeccionamiento y progresividad son finalidad y principio de educación vinculados al sentido temporalduradero de esta. La progresividad se vincula con las vivencias, por medio de la experiencia de vida; el perfeccionamiento progresivo adquiere un significado y valoración distinta en cada etapa del desarrollo humano (infancia-adolescenciajuventud-madurez-senectud); un significado distinto según la vivencia personal. Mantenemos recuerdos de vivencias pertenecientes a diversas etapas de la vida. $Y$ no se vive con la misma intensidad el tiempo en cada momento. Atendiendo a la categoría conceptual de tiempo, desde la perspectiva de la relación entre el yo 
y todo lo demás, el sentido de la educación es durable: permanente, continua, ocasional, etc., según el caso. En la educación se da un sentido de cualificación temporal (sentido de duración: a veces permanente, a veces ocasional, a veces continuo, a veces sincrónico, diacrónico, asincrónico, etcétera).

- $\quad$ Entre el otro y lo otro se da siempre desde la perspectiva del yo una relación de género cultural: toda acción educativa es cultura y es diversa y diferente, porque el yo se distingue de todo lo demás y se educa por medio de los símbolos culturales. El sentido de la educación desde la perspectiva de la relación con el otro y lo otro, atendiendo a la categoría conceptual de género, es cultural. Es una relación marcada por el principio educativo de la diversidad y la diferencia, porque cada uno es como es y cada cosa es lo que es, aunque puedan ser cambiados en la interacción. Buscamos la diversidad y la diferencia sin convertirlas en desigualdad. $\mathrm{Y}$ precisamente por eso la diversidad $\mathrm{y}$ la diferencia son principios de educación vinculados al sentido de esta. El sentido cultural de la educación debe ser entendido, dentro del conjunto "educación", como uso y construcción de experiencia axiológica sobre la diversidad y la diferencia que representan el otro y lo otro, para construirse a uno mismo y reconocerse con el otro y lo otro en un entorno cultural diverso de interacción, por medio de los valores que hay que elegir, comprometer, decidir y realizar. Asumir este principio de cualificación y sentido de la educación exige comunidad de metas y viabilidad armónica entre hombres y culturas. En la educación se da siempre un sentido cultural de cualificación de género (a veces, con respuesta intercultural; a veces, la respuesta es multicultural; a veces, es repuesta de tratamiento simétrico de las diferencias; a veces, es respuesta de tratamiento asimétrico de las diferencias; etcétera). Pero siempre es sentido cultural que adquiere diferentes respuestas en la orientación formativa temporal, respecto de la diversidad y la diferencia.

- $\quad$ Entre el yo, el otro y lo otro se da siempre la relación de formación que afecta a la condición humana, de manera general, vocacional o profesional. Cualquier área cultural puede ser instrumento para desarrollar en los educandos los valores vinculados al dominio teórico, tecnológico y práctico del área como manifestación creativa que puede conocerse, enseñarse, investigarse y realizarse. Pero el área no es solo instrumento de educación profesional. Podemos conocer un área cultural, podemos enseñar un área y podemos educar "con" el área cultural, ya sea para desarrollar en los educandos el carácter y sentido inherentes al significado de educación, ya sea para desarrollar el sentido conceptual del área dentro de la formación general de cada educando, ya sea para contribuir a formar especialistas en el área cultural desde una perspectiva vocacional o profesional. Atendiendo a la categoría conceptual de diferencia específica, desde la perspectiva de la relación entre el yo, el otro y lo otro, el sentido de la educación es formativo; toda acción educativa es formativa o no es educación. Pero no hay una única respuesta formativa; puede ser formación general, vocacional y profesional. Es siempre sentido de formación "interesada". Porque nadie está obligado a ir en la formación más allá de su interés, pensando en la profesión y en la vocación, y nadie está obligado a lograr todo en la formación general, porque en cada educando hay un límite a su capacidad de interesarse en concreto por cualquier tema. Formación e interés son principios de educación vinculados al sentido de esta. En la educación se da siempre un sentido de cualificación de la diferencia específica como formación interesada (a veces, sentido de formación general; a veces, vocacional; a veces, profesional, etcétera). 


\section{EL SIGNIFICADO DE 'EDUCACIÓN' COMO CONFLUENCIA DE CRITERIOS DE DEFINICIÓN}

Desde el conocimiento de la educación, el carácter y el sentido de la educación son los dos elementos que integran el significado desde la perspectiva de la definición real de 'educación'; el carácter determina el significado, el sentido lo cualifica. El concepto clásico de naturaleza de la educación se identifica con el concepto de carácter que yo estoy manejando, pero, en sentido amplio, de modo de ser o actuar de las cosas una vez producidas o nacidas, el concepto de naturaleza de la educación implica el carácter y el sentido, inherentes al significado de "educación", que no se confunde con las materias escolares de estudio derivadas de las áreas culturales vigentes y consolidadas en cada momento histórico.

El significado real de educación es confluencia de carácter y sentido. El carácter es el rasgo distintivo o conjunto de características que determinan a algo como lo que es. El carácter de la educación es su determinación, lo que la determina. El sentido de la educación es lo que la cualifica; es la específica perspectiva de enfoque o cualificación, que se infiere de la vinculación que se establece entre el yo, el otro y lo otro en cada acto educativo, atendiendo a las categorías conceptuales clasificatorias de espacio, tiempo, género y diferencia específica.

Desde la perspectiva de la definición real, cualquier acto de significado educativo tiene que realizarse ajustándose a las determinaciones y cualificaciones que corresponden al significado real de educación. Toda educación debe ajustarse al carácter y al sentido. La educación matemática, la educación química, la educación física, la educación literaria, la educación artística, la educación moral, la educación ciudadana, etcétera son educación porque, primariamente, cumplen las condiciones de carácter y sentido propias del significado de "educación". Pero no toda educación tiene que ser matemática, para ser educación.

Tiene sentido decir que toda educación tiene que ser personal (que es rasgo de carácter, determinante, y derivado de la complejidad objetual de 'educación'), pero no necesariamente es de matemáticas o de física o de literatura o de artes y, al mismo tiempo, tiene sentido decir que toda educación matemática, física, artística o literaria, atendiendo a la vinculación que se establece entre el yo, el otro y lo otro en cada acto educativo, debe pensarse como educación con sentido territorial, temporal, cultural y formativo.

De este modo, en cada intervención, se manifiesta el significado de la educación, como confluencia de carácter y sentido, en tanto que definición real. Pero, además, en cada intervención se manifiesta el conjunto de condiciones derivadas de los criterios de uso y actividad finalista que completan la definición, desde el punto de vista nominal. Así las cosas, el significado de 'educación' exige la confluencia de definición nominal y real, de manera que se ajuste cada actividad a criterios de uso, finalidad y de rasgos de carácter y sentido propios del término 'educación', tal como reflejamos en el Cuadro 5. 
Cuadro 5: Significado de educación como confluencia de criterios de definición

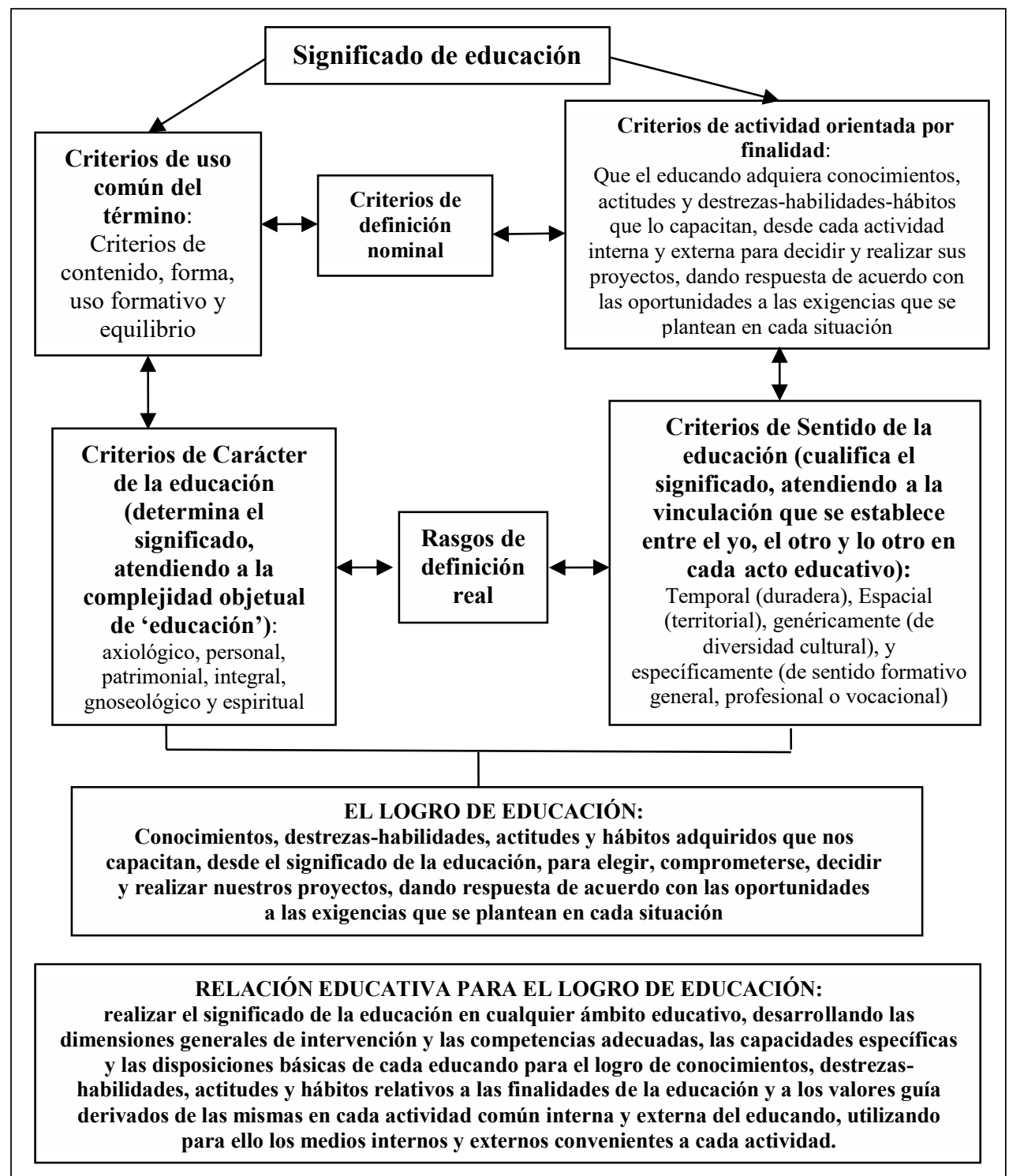

Fuente: Touriñán, 2014a, p. 651.

Atendiendo a la definición nominal y real, podemos decir que educar es, en tanto que actividad, una actividad especificada; no es cualquier actividad, si bien cualquier actividad puede ser transformada en una actividad educativa, si conseguimos que cumpla los criterios uso común, de finalidad y de significado real. La actividad educativa, para serlo, requiere el cumplimiento de las condiciones de carácter de la educación (axiológico, personal, patrimonial, integral, gnoseológico y espiritual) y las condiciones de sentido de la educación (territorial, duradera, de diversidad cultural y específicamente formativa con sentido general, profesional y vocacional), así como los criterios de uso y finalidad. 
7. EL CONCEPTO DE 'EDUCACIÓN' COMO CONFLUENCIA DE SIGNIFICADO Y ORIENTACIÓN FORMATIVA TEMPORAL en cada intervención, contando con LA ACTIVIDAD COMÚN interna y externa

Desde el punto de vista del conocimiento de la educación, resulta útil distinguir dos tipos de fines:

- $\quad$ Fines intrínsecos, porque se deciden en el sistema y su contenido es conocimiento de la educación en el sentido de las decisiones técnicas vinculadas a los rasgos propios del significado de la educación (metas pedagógicas).

- $\quad$ Fines extrínsecos porque, si bien se deciden en el sistema con el amparo del conocimiento de la educación valioso, su contenido es contenido sociocultural legitimado práxicamente como bueno para la educación en un momento y lugar sociohistórico concreto, en el sentido de las decisiones práxicas -morales y políticas- (metas educativas).

Ambos tipos de fines están sometidas al carácter histórico. Pero su origen es distinto, por el tipo de discurso que lo justifica; en un caso decimos que el hombre debe expresarse histórica y literariamente, por ejemplo, para estar educado en esta época (finalidad extrínseca) y en el otro decimos hay que desarrollar sentido crítico, porque sin él, el hombre no podrá educarse (finalidad intrínseca, propia de la actividad interna del educando identificada como "pensar"). En el primer caso, el hombre estará más o menos educado, según en qué áreas sepa expresarse; en el segundo caso, el hombre, si no tiene sentido crítico formado, no tendrá educación, porque el criterio y la racionalidad son rasgos de necesidad lógica respecto del concepto 'educación', vinculados al carácter de la educación.

Parece razonable afirmar que una manera de diferenciar las finalidades intrínsecas $y$ extrínsecas consiste en distinguir "necesidad lógica de algo" (¿Qué es lo que hace que algo sea educación?, -criterios y rasgos de significado que determinan y cualifican como educación-) y "expectativas socioculturales dirigidas al sistema educación" que expresan lo que la sociedad espera de la educación. Necesidad lógica y expectativa se integran en la "orientación formativa temporal de la condición humana", individual, social, histórica y de especie, en un momento concreto (¿cuál es el hombre educado de cada época?). En ambos casos debemos fundamentar nuestra decisión de determinación de fines, apelando al significado de la educación (Touriñán, 2015 y 2014c).

Así las cosas, se confirma una vez más en este discurso que los conocimientos teóricos, tecnológicos y práxicos (de la Literatura, la Historia, la Filosofía, la experiencia de vida, la Moral, las costumbres, etc.,) de las diversas áreas culturales que se constituyen en objetivo de conocimiento en la enseñanza, no los crean los profesionales de la educación con su conocimiento especializado (conocimiento de la educación); son los especialistas de cada una de esas áreas los que los crean y pueden convertirse en metas social y moralmente legitimadas en esa sociedad. Justamente por eso, son candidato a meta de la educación. Si además de estar legitimados social y moralmente, son elegidos, porque se justifican desde los criterios y rasgos propios del significado de 'educación', pasan a ser, no candidato a meta educativa, sino efectiva finalidad extrínseca (Touriñán, 2019d y 2019e).

Las finalidades intrínsecas, por su parte, son las que se deciden en el sistema y su contenido es conocimiento de la educación. La validez de sus enunciados no procede sin más de su carácter social y moralmente deseable, o de su validez en un área cultural, sino de las pruebas específicas del ámbito, es decir, a partir del significado que se les atribuye a los enunciados desde el sistema conceptual elaborado con el conocimiento de la educación. 
Desde la perspectiva de los rasgos de carácter y sentido pedagógico que determinan y cualifican el significado de educación, se infieren las finalidades intrínsecas, autóctonas, que denominamos con rigor lógico, metas pedagógicas: sabiduría, felicidad, determinación, libertad, autonomía, salud física y mental, convivencia, perfeccionamiento, instrucción y formación (Touriñán, 2017).

Estas metas pedagógicas se fundamentan desde los rasgos de carácter y sentido inherentes al significado de educación (carácter gnoseológico, integral, personal, axiológico, patrimonial y espiritual y sentido territorial, duradero, cultural y formativo) por medio de los principios derivados de esos rasgos (principios de integración cognitivo-comprensiva -comprensión-, de integración afectiva-expresión positiva-, de originalidad y compromiso -autenticidad y autoctonía-, de responsabilidad y sentido de acción -coherencia-, de identidad, individualización y sentido de vida -idoneidad-, de integración creativa -interpretación de símbolos), de socialización, de progresividad, de diversidad y diferenciación y de interés.

Podemos decir que las finalidades intrínsecas se conocen frecuentemente como metas pedagógicas, son finalidades vinculadas al proyecto educativo y nacen del conocimiento de la educación. Las finalidades extrínsecas se conocen genéricamente -a falta de un nombre más específico- como metas educativas. Las primeras se identifican con lo propio de los criterios de significado que hacen posible que algo sea 'educación' y no otra cosa; las segundas de identifican con la orientación sociohistórica de la educación, con lo que la sociedad espera de la educación. Ambas finalidades se integran en la orientación de la respuesta formativa temporal para la condición humana en cada época, sin contradicción con el significado de educación (Touriñán, 2013b). condición humana es el modelo o patrón educativo de esa sociedad (el tipo de personas que queremos hacer con la formación que les damos en un determinado momento histórico). Por medio de la intervención, transformamos en educación el conocimiento de áreas culturales, en cada ámbito de educación que construimos.

La orientación formativa temporal integra el contenido de la educación y permite concretar y diferenciar la respuesta educativa correspondiente en cada territorio a cuestiones centrales y complementarias del concepto de educación, respecto de lo permanente y lo cambiante, lo esencial y lo existencial, lo estructural y lo funcional, lo que corresponde al ser o al devenir de la educación en cada momento socio-histórico concreto y que se plasma en la arquitectura curricular y en los ámbitos de educación que construimos, tal como queda recogido en el Cuadro 6. 
Cuadro 6: Concepto de educación como confluencia de significado y orientación formativa temporal

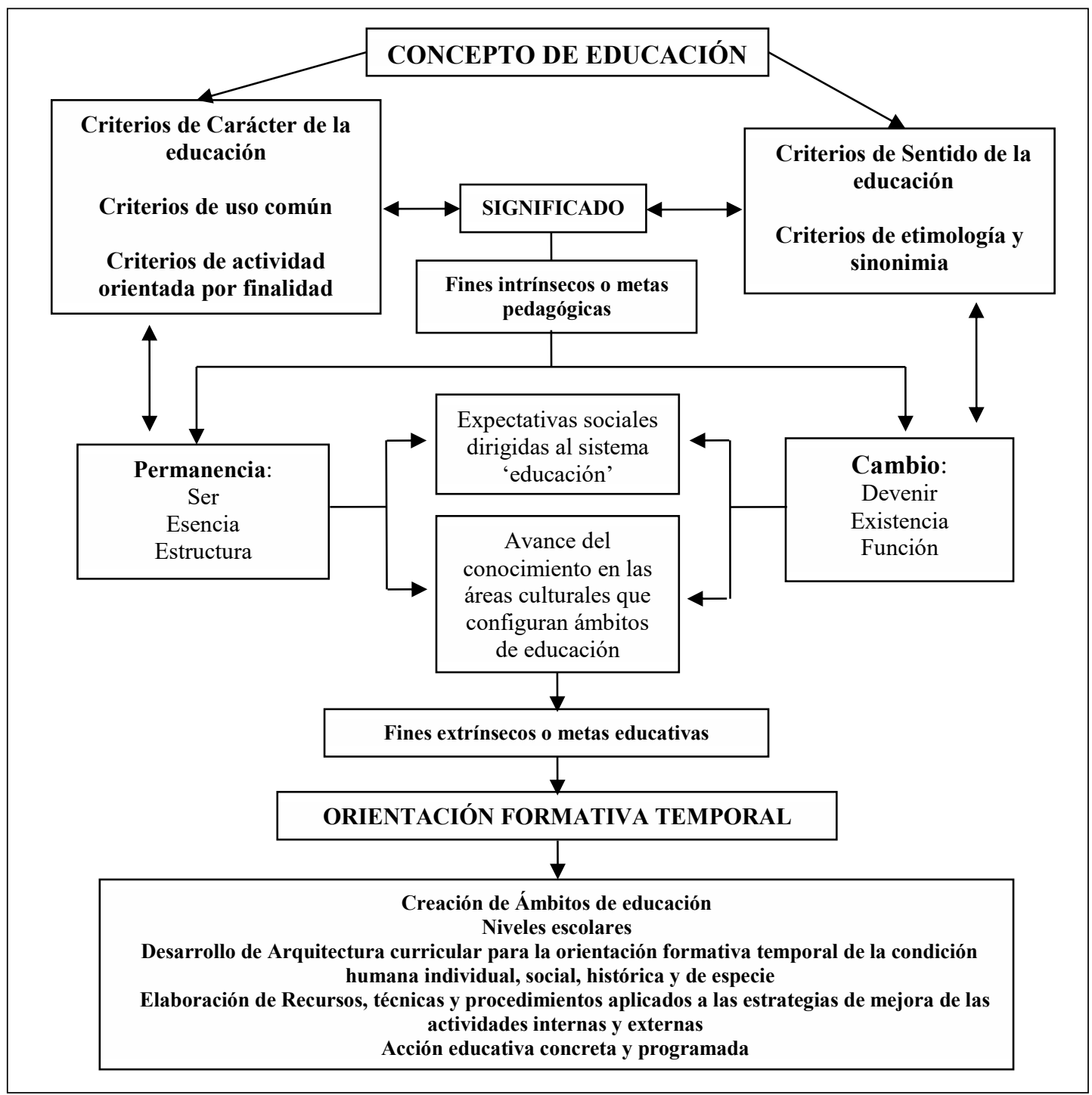

Fuente: Touriñán, 2014a, p. 656.

Toda orientación formativa temporal conjuga tradición e innovación, el cultivo de lo personal y el compromiso con la grandeza de miras, porque ese es el marco en el que se mueven los fines de la educación que nacen de las expectativas sociales dirigidas al sistema. Se conjuga tradición e innovación (a veces, enmascarado en los términos modernidad y progreso), no por puro capricho particular del político de turno, sino porque, asumiendo el carácter de responsabilidad compartida en la educación, todos reconocen participativamente que, a la hora de definir el humano que queremos formar, ni todo en la tradición es rechazable, ni solo las innovaciones responden al conocimiento que debe conservarse. Se conjuga el cultivo de lo personal y la grandeza de miras, porque la educación, entendida en su sentido pleno, no alcanza su objetivo con desarrollar un hombre capaz de valerse por sí mismo y para sí mismo. Además, debe entenderse que este núcleo personal no estará conseguido mientras que la educación no salvaguarde y cultive en cada educando el sentido de la relación con el otro y lo otro, es decir el sentido social de la diversidad y la identidad en los espacios de convivencia. 
Y esto implica llegar a asumir el compromiso con los principales derechos y obligaciones que como ciudadanos y como miembros de la comunidad deben cumplirse en el marco legal territorializado. La orientación formativa temporal responde al significado de educación y a las expectativas sociales dirigidas al sistema en forma de cumplimiento de las funciones que se le atribuyen, en tanto que la educación es factor de desarrollo social.

Los distintos modos de abordar la educación, desde la perspectiva del conocimiento pedagógico, permiten hablar siempre de ella como un valor elegido con finalidad educativa. Desde el punto de vista de la intervención, la educación está comprometida con finalidades extrínsecas o metas educativas y con finalidades intrínsecas o metas pedagógicas para lograr en la intervención el cumplimiento de exigencias lógicas del significado de la educación que determinan y cualifican destrezas, hábitos, actitudes, conocimientos y competencias como componentes de valor educativo reconocido para construirse a uno mismo, o lo que es lo mismo, para educarse.

La orientación formativa temporal está elaborada a partir de la singularidad de las situaciones, del conocimiento de la educación generado, del avance de las áreas culturales y de la pertinencia y relevancia de los valores vigentes dentro de una determinada sociedad. Las materias escolares se agrupan en la arquitectura curricular, atendiendo a los niveles del sistema educativo, respetando los criterios y rasgos de definición nominal y real de educación. Y, desde áreas culturales, vigentes, consolidadas y transformadas en ámbitos de educación, la orientación formativa temporal para la condición humana, oferta el patrón, modelo educativo en cada sociedad concreta, en el marco de identidad, diversidad y territorialidad.

Por medio de las materias escolares, la orientación formativa se aplica y se nutre desde estratos de pensamiento, derivados de diversas áreas culturales y variada condición, que van desde el humanismo al comunitarismo, desde el nacionalismo al individualismo, de la ética a la estética, de la moral a la religión, de la filosofía a la ciencia, de lo antropológico a lo cultural y así sucesivamente. La educación no se confunde, ni se identifica con esos estratos necesariamente, porque el significado de la educación es específico, distinto y propio de ese ámbito de realidad que es la educación y ajustado a definición nominal y real. La educación, tendrá orientación formativa temporal en la política educativa de perfil socialista, humanista, comunitario, laico, confesional, aconfesional, etc., según sea el momento histórico y atendiendo a la mayor o menor preponderancia de un determinado tipo de mentalidad ciudadana; son los sentidos filosóficos de la educación vinculados a expectativas sociales (Pring, 2014). Pero, además, en todos esos casos la educación es educación sustantivamente y por ello mantiene -tiene que mantener, so pena de perder su condición propia- coherencia con el significado de educación, con los rasgos de carácter y sentido que son inherentes al significado de 'educación'. De este modo, la educación podrá ser socialista, humanista, etc., pero solo será necesariamente educación, si cumple las condiciones de carácter y sentido propias del significado: toda educación es educación, porque tiene carácter axiológico, personal, patrimonial, integral, gnoseológico y espiritual y porque tiene sentido territorial, duradero, cultural y formativo en cada una de sus acciones. De este modo la acción educativa no dejará de ser educación y no se convertirá en canal propagandístico de las ideas políticas del grupo dominante (Touriñán, 2017a y 2020a; Touriñán y Longueira, 2018).

$Y$ esto es así, porque, en concepto, la educación es un proceso de maduración y construcción que implica realizar el significado de la educación en cualquier ámbito educativo, 
desarrollando las dimensiones generales de intervención y las competencias adecuadas, los hábitos fundamentales de desarrollo, las capacidades específicas y las disposiciones básicas de cada educando para el logro de las finalidades de la educación y los valores guía derivados de las mismas. No por otra cosa, sino por esta, decimos que, la educación es uso y construcción de experiencia axiológica para elegir, comprometerse, decidir y realizar un proyecto personal de vida, dando respuesta de acuerdo con la oportunidades a las exigencias que se plantean en cada situación; es una actividad, en definitiva, orientada a construirse a uno mismo y reconocerse con el otro y lo otro en un entorno cultural diverso de interacción, por medio de los valores que hay que elegir, comprometerse, decidir y realizar.

En la relación educativa, por tanto, buscamos la concordancia valores-sentimientos en cada interacción y para ello elegimos, nos comprometemos, decidimos y realizamos lo decidido. $Y$ para realizar, ejecutamos mediante la acción lo comprendido e interpretado, expresándolo. La realización exige ejecutar mediante la acción. Y esa acción, además de la actividad común interna del sujeto, utiliza siempre la actividad común externa del educando. Realizamos por medio del juego, del trabajo, del estudio, de la indagación-exploración, de la intervención en cada acto y de la relación que se establezca entre el yo y las cosas usadas en cada interacción, que está definida siempre como relación yo-el otro-lo otro. $Y$ todo esto es visto por el educador en la relación educativa como medios para la acción.

Finalmente, como hemos expuesto en el epígrafe dedicado a la función pedagógica, nos educamos con la actividad común interna. Pero, además, nos educamos por medio de la actividad común externa (estudiando, jugando, trabajando, indagando-explorando, interviniendo y relacionándonos con el yo, el otro y lo otro), porque al ejercer una concreta actividad común externa activamos las capacidades comunes internas, las entrenamos, las ejercitamos, las ejercemos y las mejoramos para hacer bien cada actividad común externa. La actividad común externa, por principio de actividad, activa la actividad común interna en cada ejecución concreta de la actividad común externa, sea esta jugar, estudiar, trabajar, indagar, intervenir o relacionar. Al ejecutar la actividad común externa, mejoramos y entrenamos las actividades-capacidades internas: $\sin$ la actividad es imposible educar y gracias a ella se hace posible que el educando sea agente actor y cada vez mejor agente autor de su propios proyectos y actos.

\section{CONSIDERACIONES FINALES EN ORDEN A CONSTRUIR ÁMBITOS DE EDUCACIÓN: TRIPLE ACEPCIÓN TÉCNICA DEL ÁREA CULTURAL COMO ÁMBITO DE EDUCACIÓN}

Desde la perspectiva del conocimiento de la educación se identifican y definen, atendiendo al sentido formativo de 'educación', tres acepciones posibles de las áreas culturales como instrumento de educación, en cualquiera de sus manifestaciones y que dan significado a la relación áreas culturales-educación "como educación", "como experiencia cultural" y "como experiencia profesional y vocacional", es decir, se justifica la diferencia conceptual del área cultural como ámbito de educación, tal como queda reflejado en el Cuadro 7: 
Cuadro 7: La triple acepción técnica de área cultural como ámbito de educación

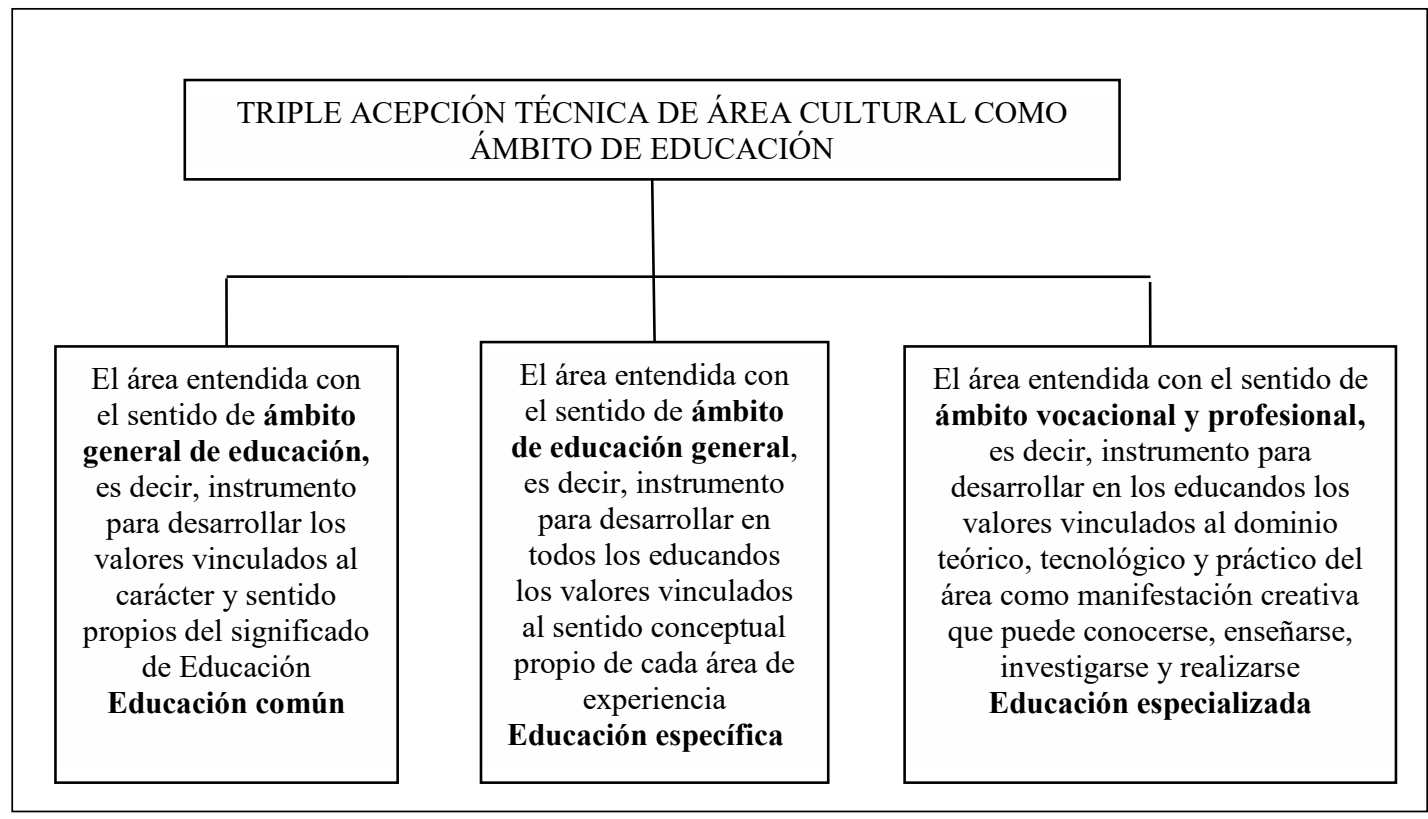

Fuente: Touriñán, 2014a, p. 659.

En las dos primeras acepciones, por medio del área cultural se realizan los fines de la educación en general, vinculadas al significado de "educación", y los fines de la educación general identificables desde el sentido conceptual del área cultural. En la tercera acepción se cubre el sentido propio de la educación desde el área cultural como orientación profesional y vocacional para un área determinada. En las dos primeras acepciones, damos contenido a la expresión "educación por el área cultural". En la tercera acepción damos contenido a la expresión "educación para un área cultural".

Para nosotros, el área cultural contemplada desde la perspectiva de ámbito de educación no es sólo educación "para" un área cultural (desarrollo vocacional y carrera profesional), centrado preferentemente en el área como conocimiento teórico, ámbito de investigación y actividad creativa, cuyo dominio técnico y ejecución práctica pueden enseñarse. El área cultural también es educación "por" el área cultural (ámbito general de educación y ámbito de educación general), ámbito general de educación que permite focalizar la intervención pedagógica en el área cultural al desarrollo del carácter y sentido propio de la educación, -como se debería hacer con las matemáticas, la lengua, la geografía, o cualquier disciplina básica del currículum de la educación general- y ámbito de educación general en el que se adquieren competencias para el uso y construcción de experiencia valiosa sobre el sentido conceptual del área, asumible como acervo común para todos los educandos como parte de su desarrollo integral. Podemos conocer un área cultural, podemos enseñar un área y podemos educar "con" el área cultural, ya sea para desarrollar en los educandos el carácter y sentido inherentes al significado de educación, ya sea para desarrollar el sentido conceptual del área dentro de la formación general de cada educando, ya sea para contribuir a formar especialistas en el área cultural desde una perspectiva vocacional o profesional (Touriñán, 2015 y 2019f).

Así las cosas, podemos hablar, con propiedad, de educación "para" un área cultural (la de mi vocación o la de mi profesión), pero, además, 
podemos hablar de educación general "por" el área cultural. La educación CON un área cultural, además de ser un ámbito de formación vocacional y de desarrollo profesional, es un ámbito general de educación, pero es también un ámbito de educación general, por eso puede impartirse a los educandos como educación común y como educación general y básica.

La educación CON un área cultural, como ámbito general de educación, cumple las condiciones propias de los ámbitos generales de educación: se ajusta a valores derivados de los criterios de significado de 'educación'. Y precisamente por eso, es obligado no confundir las tres acepciones posibles del área cultural como problema de educación, y que son las que dan significado a la relación "área culturaleducación" como experiencia educativa común, como experiencia educativa específica y experiencia educativa especializada (Touriñán, 2021, 2016 y 2019f):

- $\quad$ El área cultural como ámbito general de educación que aportan valores educativos comunes vinculados al carácter $y$ al sentido propios de la educación, son valores inherentes al significado de educar

- $\quad$ El área cultural como ámbito de educación general, que aporta valores educativos específicos vinculados al sentido conceptual propio de cada área cultural usada para educar. Son valores vinculados al significado de cada area cultural. Qué es, cómo mejora mi capacidad de tomar decisiones, cómo me forma, cómo me ayuda a construir mi proyecto de vida

- $\quad$ El área cultural como ámbito de desarrollo profesional y vocacional que aporta valores educativos especializados por medio del conocimiento teórico, tecnológico y práctico del área.
Esas propuestas permiten identificar cada vez mejor la educación: en primer lugar, como educación común (ámbito general de educación); en segundo lugar, como educación específica (ámbito de educación general) y, en tercer lugar, como educación especializada (ámbito profesional y vocacional).

La pedagogía forma criterio acerca de los ámbitos de educación en el sentido genérico de entender cada área cultural como ámbito de educación. Este es un objetivo que solo se resuelve desde la Pedagogía, porque cada área cultural tiene que integrar los rasgos de carácter y sentido que son propios del significado de educación. Para ello, el área de experiencia cultural tiene que ser construida como ámbito de educación, ya sea ámbito general de educación, ámbito de educación general o ámbito de educación vocacional y profesional (ámbito de educación común, específico y especializado). $Y$ esto es factible, si interpretamos y comprendemos el área cultural desde la perspectiva del conocimiento de la educación que proporciona la Pedagogía Mesoaxiológica, porque a la pedagogía le corresponde valorar cada área cultural como educación y construirla como "ámbito de educación" (Touriñán, 2017a y 2017b).

La Pedagogía se especifica necesariamente como pedagogía mesoaxiológica, porque es objetivo de la pedagogía transformar la información en conocimiento y el conocimiento en educación, construyendo ámbitos de educación desde las diversas áreas culturales. Cada área cultural es un área de experiencia cognoscible, enseñable, investigable y realizable que puede constituirse en objeto y meta de la educación, transformándose en ámbito de educación. Estamos en condiciones de ir desde la pedagogía general a las pedagogías aplicadas construyendo ámbitos de educación, haciendo el diseño educativo derivado y generando la intervención pedagógica pertinente. 


\section{REFERENCIAS BIBLIOGRÁFICAS}

Arendt, H, (1974). La condición humana. Barcelona: Seix Barral.

Ausubel, D. P. (1982). Psicología educativa. Un punto de vista cognoscitivo. México: Trillas, $4^{a}$ reimp. (Fecha de edición original, 1968).

Ballester, L. y Colom, A. J. (2017). Epistemologías de la complejidad y educación. Barcelona: Octaedro.

Bateson, G. (1979). Mind and Nature: A Necessary Unity (Advances in Systems Theory, Complexity, and the Human Sciences). New York: Hampton Press.

Berlo, D. K. (1979). Elproceso dela comunicación. Introducción a la teoría y a la práctica. Buenos Aires: El Ateneo, $10^{\mathrm{a}}$ reimp.

Bunge, M. (1975). Teoría y realidad. Barcelona: Ariel, $2^{\mathrm{a}}$ ed.

Carr, D. (2014). Diverse Senses, and Six Conceptions, of Education. Revista española de pedagogía, 72 (258), 219-230.

Colbert, J. G. (1969). Método. Gran Enciclopedia Rialp. Madrid: Rialp, pp. 667-669.

Colom, A. J. (2008). Per a una pedagogía del laberint. Palma: Univeristat de les Illes Balears.

Damasio, A. (2010). Y el cerebro creó al hombre. Barcelona: Destino, $2^{\mathrm{a}}$ ed. (Original de 2010).

Dearden, R. F.; Hirst, P. H. y Peters, R. S. (Eds.) (1982). Educación y desarrollo de la razón. Formación del sentido crítico. Madrid: Narcea.
Dewey, J. (1998). Cómo pensamos. Nueva exposición de la relación entre pensamiento reflexivo $y$ proceso educativo. Barcelona: Paidós.

Díaz Barriga, F. (2006). Enseñanza situada. Vínculo entre la escuela y la vida. México: McGrawHill.

Esteve, J. M. (2010). Educar: un compromiso con la memoria. Un libro para educar en libertad. Barcelona: Octaedro.

Ferrater, J. (1979). De la materia a la razón. Madrid: Alianza Universidad.

García Aretio, L.; Ruiz Corbella, M. y García Blanco, M. (2009). Claves para la educación. Actores, agentes y escenarios en la sociedad actual. Madrid: Narcea.

Gervilla, E. (2000). Valores del cuerpo educando. Antropología del cuerpo y educación. Barcelona: Herder.

González Álvarez, A. (1947). El principio fundamental de la Metodología. Revista Española de Pedagogía, 5 (17), 7-23.

González, N.; Moll, L. C. y Amanti, K. (2005). Funds of Knowledge: Theorizing Practices in Households, Communities, and Classrooms. Mahwah, N. J.: Lawrence Erlbaum Associates.

Haidt, J. (2006). La hipótesis de la felicidad. La búsqueda de verdades modernas en la sabiduría antigua. Barcelona: Gedisa.

Ladriére, J. (1977). El reto de la racionalidad. Salamanca: Sígueme.

Lipovetsky, G. (1986). La era del vacío. Ensayo sobre el individualismo contemporáneo. Barcelona: Anagrama. 
Luhman, N. (1983). Fin y racionalidad de los sistemas. Sobre la función de los fines en los sistemas sociales. Madrid: Editora Nacional.

Lyotard, J. F. (1984). La condición postmoderna. Madrid: Cátedra.

Mantovani, J. (1972). La educación y sus tres problemas. Buenos Aires: El Ateneo. $9^{\mathrm{a}}$ ed.

Marina, J. A. (2009). El aprendizaje de la sabiduría. Aprender a vivir/ aprender a convivir. Barcelona: Ariel.

Maslow, A. H. (1982). La amplitud potencial de la naturaleza humana. México: Trillas.

Morin, E. (2009). El método 5. La humanidad de la humanidad. Madrid: Cátedra. $4^{\mathrm{a}}$ ed.

Mosterín, J. (2008). La naturaleza humana. Madrid: Espasa Calpe.

Novak, J. D. (1998). Conocimiento y aprendizaje. Los mapas conceptuales como herramientas facilitadoras para escuelas y empresas. Madrid: Alianza Editorial.

Peters, R. S. (1979). Ethics and education. Londres: G. Allen and Unwin, $1^{\mathrm{a}}$ ed. $7^{\mathrm{a}}$ reimp.

Pinker, S. (2003). La tabla rasa. La negación moderna de la naturaleza humana. Madrid: Paidós.

Pinker, S. (2011). Cómo funciona la mente. Barcelona: Destino. $3^{\mathrm{a}}$ reimp. (Original de 1997).

Polanyi, M. (1978). Personal Knowledge. Towards a Postcritical Philosophy. Londres: Routledge and Kegan Paul.

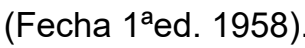

Prigogine, I. (1997). El fin de las certidumbres. Madrid: Tecnos.

Prigogine, I. y Stengers, I. (1983). La nueva alianza. Metamorfosis de la ciencia. Madrid: Alianza Universidad.

Pring, R. (2014). From Disguised Nonsense to Patent Nonsense: Thinking Philosophically. Revista española de pedagogía, 72 (258), 231-248.

Quintana, J. Mª (1988). Teoría de la Educación. Concepción antinómica de la educación. Madrid: Dykinson.

Reig, D. (2012). Zonas de Desarrollo Próximo, Entornos Personales de Aprendizaje e Internet como Derecho Fundamental. Consultado 27 de febrero de 2013. http://www.dreig.eu/caparazon

Sáez Alonso, R. (2007). La Teoría de la Educación: Una búsqueda sin término en la construcción del conocimiento de la Educación. Encounters on Education, (8), 109-126.

Scheffler, I. (1970). El lenguaje de la educación. Buenos Aires: El Ateneo.

SI(e)TE. Educación (2016). Repensar las ideas dominantes en la educación. Santiago de Compostela: Andavira.

SI(e)TE. Educación (2018). La Pedagogía, hoy. Santiago de Compostela: Andavira.

SI(e)TE. Educación (2020). Saber para hacer en educación. Santiago de Compostela: Andavira.

Sztajn, P.; Confrey, J.; Wilson, P. H. y Edington, C. (2012). Learning Trajectory Based Instruction: Toward a Theory of Teaching. Educational Researcher, 41 (5), 147-156. 
Touriñán, J. M. (2013a). Conocer, enseñar y educar no significan lo mismo. El carácter y el sentido de la educación como referentes de su significado desde la mirada pedagógica. Teoría de la educación. Revista interuniversitaria, 25 (1), 25-46.

Touriñán, J. M. (2013b). ¿Enseñar áreas culturales o educar con las áreas culturales?, en SI(e)TE (2013). Desmitificación y crítica de la educación actual. Barcelona: Octaedro, pp. 5792.

Touriñán, J. M. (2014a). Dónde está la educación. Actividad común interna y elementos estructurales de la intervención. A Coruña: Netbiblo.

Touriñán, J. M. (2014b) Dónde está la educación. Definir retos y comprender estrategias A propósito de un libro de 2014. REINED, 12 (1), 6-31.

Touriñán, J. M. (2014c). Conocer, enseñar y educar no son lo mismo desde la mirada pedagógica. El reto de la construcción de ámbitos de educación. Boletín REDIPE, 3 (3), febrero, 6-30.

Touriñán, J.M.(2015).Pedagogíamesoaxiológica y concepto de educación. Santiago de Compostela: Andavira. $2^{a}$ edición disponible de 2016 .

Touriñán, J. M. (2016). Pedagogía general. Principios de educación y principios de intervención. A Coruña: Bello y Martínez.

Touriñán, J. M. (2017a). Mentalidad pedagógica y diseño educativo. De la pedagogía general a las pedagogías aplicadas en la función de educar. Santiago de Compostela: Andavira.
Touriñán, J. M. (2017b). El concepto de educación: carácter, sentido pedagógico, significado y orientación formativa temporal. Hacia la construcción de ámbitos de educación. Revista Boletín Redipe, 6 (12), diciembre, 24-65.

Touriñán, J. M. (2018). Concepto de educación y conocimiento de la educación. The Concept of Education and the Knowledge of Education. ColombiaNueva York: Redipe (Bowker-Books).

Touriñán, J. M. (2019a). Estudiar es actividad común externa y siempre educamos con la actividad. Una aproximación desde la perspectiva mesoaxiológica. Teoría de la Educación. Revista interuniversitaria, 31 (2), 7-39.

Touriñán, J. M. (2019b). La relación educativa es un concepto con significado propio que requiere concordancia entre valores y sentimientos en cada interacción. Sophia, colección de Filosofía de la Educación, 26 (1), 223-279.

Touriñán, J. M. (2019c). Imagen social de la Pedagogía. Competencia técnica y educación de calidad, en C. Naval, J. Vergara, A. Rodríguez y A. Bernal (Coords.), Reflexiones teóricas sobre la educación. Madrid; Dykinson, pp. 145192.

Touriñán, J. M. (2019d). ¿Qué estamos haciendo mal? Una reflexión desde la Pedagogía, en $\mathrm{A}$. de la Herrán, J. M. Valle y J. L. Villena (Coords.), ¿Qué estamos haciendo mal en la educación? Reflexiones pedagógicas para la investigación, la enseñanza y la formación. Barcelona: Octaedro, pp. 287-330. 
Touriñán, J. M. (2019f). Valores educativos comunes y específicos: análisis descriptivo de su integración pedagógica en las materias escolares a partir de la percepción de los docentes sobre su actividad. Revista Boletín Redipe, 8 (6), junio, 23-49.

Touriñán, J. M. (2019e). Pedagogía, profesión, conocimiento y educación: una aproximación mesoaxiológica a la relación desde la disciplina, la carrera y la función de educar. Tendencias Pedagógicas, (34), 93-115.

Touriñán, J. M. (2020a). Pedagogía, competencia técnica y transferencia de conocimiento. La perspectiva mesoaxiológica de la Pedagogía. Santiago de Compostela: Andvira.

Touriñán, J. M. (2020b). Los medios y su valor pedagógico en la relación educativa, en A. Medina, A. de la Herrán y $\mathrm{M}^{\mathrm{a}}$ C. Domínguez, Hacia una Didáctica humanista. Colombia-Madrid: Redipe (Bowker Books in print)-UNED, pp. 199268.

Touriñán, J. M. (2021). Pedagogía de las artes. La perspectiva mesoaxiológica. Santiago de Compostela: Andavira.

Touriñán, J. M. (Dir.) (2012). Desarrollo cívico, sentido intercultural de la educación y convivencia cualificada y especificada. Coruña: Netbiblo.

Touriñán, J. M. y Longueira, S. (Coords.) (2018). La construcción de ámbitos de educación. Pedagogía general y aplicada. Santiago de Compostela: Andavira.

Touriñán, J. M. y Sáez, R. (2006). La metodología de investigación y la construcción del conocimiento de la educación. Revista galega do ensino, $2^{\mathrm{a}}$ época, 14 (48), 89-130 y $377-410$.

Touriñán, J. M. y Sáez, R. (2012). Teoría de la educación, metodología y focalizaciones. La mirada pedagógica. A Coruña: Netbiblo. Hay edición actualizada en Touriñán, J. M. y Sáez, R. (2015). La mirada pedagógica. Teoría de la educación, metodología y focalizaciones. Santiago de Compostela: Andavira.

Zubiri, X. (1978). Naturaleza, Historia, Dios. Madrid: Editora Nacional, $7^{a}$ ed.

Zubiri, X. (2006). Tres dimensiones del ser humano: individual, social, histórica. Madrid: Alianza Editorial. Fundación Xabier Zubiri. 